\title{
Technological innovation and employment in derived labour demand models: A hierarchical meta-regression analysis
}

\author{
Mehmet Ugur*, Sefa Awaworyi Churchill ${ }^{\#}$ and Edna Solomon* \\ * Greenwich Political Economy Research Centre, University of Greenwich Business School \\ \# Department of Economics, Monash University Business School
}

\begin{abstract}
The effect of technological innovation on employment is of major concern for workers and their unions, policy-makers and academic researchers. We Meta-analyse 570 estimates from 35 primary studies that estimate a derived labour demand model. We contribute to existing attempts at evidence synthesis by addressing the risks of selection bias and that of data dependence in observational studies. Our findings indicate that: (i) hierarchical metaregression models are sufficiently versatile for addressing both selection bias and data dependence in observational-data studies; (ii) innovation's effect on employment is positive but small and highly heterogeneous; (iii) only a small part of residual heterogeneity is explained by moderating factors; (iv) selection bias tends to reflect preference for upholding prevalent hypotheses on the employment-effects of process and product innovations; (v) country-specific effect-size estimates are related to labour-market and product-market regulation in six OECD countries in a U-shaped fashion; and (vi) OLS estimates reflect upward bias whereas those based on time-differenced or within estimators reflect a downward bias. Our findings point out to a range of data quality and modeling issues that should be addressed in future research.
\end{abstract}

Keywords: Innovation, employment, technological change, labour demand, meta-analysis

The research for this paper is part of an ESRC Project titled Evaluation of Research and Development (R\&D) Expenditures, Firm Survival, Firm Growth and Employment: UK Evidence in the OECD Context. Reference no $\mathrm{ES} / \mathrm{K} 004824 / 1$. We thank the funders for their support. We also thank two anonymous reviewers and the editor for helpful and insightful comments that have improved the quality of the paper. The usual disclaimer applies: views expressed here are those of the authors only, who are responsible for any errors or omissions. 


\section{Technological innovation and employment in derived labour demand models: A hierarchical meta-regression analysis}

\section{Introduction}

The effect of technological change on employment has always divided opinions. Since the Luddite riots of the early $19^{\text {th }}$ century in England, workers and their unions have emphasized the risks of de-skilling and technological unemployment. Against this, business managers and policy makers tended to consider technological change as essential for growth and job creation. In between, economic theory calls for qualified conclusions: whilst technological innovation may be associated with worker displacement in the short run, the effect is more likely to be positive in the long run as compensation mechanisms induce higher demand for labour.

Several narrative reviews of the extant literature exist. Chennells and van Reenen (2002) discuss the variation in the evidence base in the light of modeling, estimation and data-related issues. Others reviews pay attention to additional sources of heterogeneity such as compensation mechanisms, levels of development, and types of technological innovation among others (Spiezia et al., 2002; Piva, 2003; Pianta, 2004; and Vivarelli (2014). Existing narrative reviews offer three general conclusions. First, the effect of technological innovation on employment is contingent on a wide range of moderating factors, including labour market flexibility, product market competition, types of innovation, national innovation systems, and international trade. Second, the balance of evidence does not point out a negative effect on employment, but process innovation is more likely to be associated with job destruction whereas product innovation is more likely to be associated with job creation. Finally, the effect is more likely to be negative when the data relates to unskilled labour.

We have identified a number of issues that justify a systematic review. First, existing reviews pool evidence based on three different models (derived labour demand, skill/wage share and innovation-decomposition models), which may yield non-comparable estimates. Secondly, reviewer authors are aware of the heterogeneity in the evidence base, but their conclusions concerning the sources of heterogeneity require quantitative verification. Third, existing reviews do not take into account the risk of publication selection bias, which may arise when 
authors or editors choose to publish findings that support or reject a given hypothesis more often than contradictory or insignificant findings. Fourth, conclusions based on narrative reviews do not take account of data dependence that may arise when primary studies draw on the same or overlapping datasets. Finally, and despite the significant role accorded to labourand product-market flexibility in the theoretical models, existing reviews do not evaluate systematically the effect of labour or product market institutions on primary-study findings.

We aim to address these issues through meta-regression analysis, a quantitative method of literature review that has been used extensively in medical research and has gathered momentum in economics research (Stanley and Doucouliagos, 2012; Stanley et al., 2013). Focusing on comparable estimates based on a derived labour demand model, we report the following findings: (i) the extent of between-study heterogeneity is high (over 75\%) in the full sample and in some sub-samples of the evidence base; (ii) the effect-size is positive but small in the full sample and in subsamples of paired innovation and skill types; (iii) the effect on unskilled labour demand is smaller than skilled or mix-skills labour demand, but there is no systematic difference between the latter; (iv) there is evidence of moderate positive publication selection bias in the overall evidence base, but the bias is larger in process and product innovation subsamples and reflects selection in favour of prevalent hypotheses; (v) the evidence for six OECD countries reveals a U-shaped relationship between the 'effect-size' estimates and labour/product market regulation; and (vii) although the effect is larger in primary studies published after 2000 , it is relatively smaller when the primary studies use panel data and instrumental variable estimation methods, data related to high-innovation-intensity firms/industries and intellectual property assets as a proxy for innovation.

The rest of the paper is organised as follows. In section 2, we summarise the existing review findings and highlight the issues that cannot be addressed effectively in narrative reviews in general. Section 3 introduces the derived labour demand model and discusses why we restrict our sample to primary studies that draw on this model only. In section 4 we report the systematic review rules and provide an overview of the evidence base with respect to dimensions such as study type/date, model specification, sample characteristics, and estimation methods. In section 5, we introduce the bivariate and multivariate meta-regression models and discuss how we choose the appropriate estimators. Section 6 reports the meta-regression findings and compare the latter with theoretical predictions and narrative review findings. In the conclusions, we discuss the implications for future research. 


\section{Technological innovation and employment: what do we know?}

Writing only a few years after the Luddite Riots, Riccardo was of the view that the "substitution of machinery for human labour is often very injurious to the interests of the class of labourers." (Quoted in Mokyr et al, 2015: 33). Marx went further by arguing that "the machine can only be employed profitably, if it ... is the product of far fewer men than it replaces" (quoted in Vivarelli, 2014: 127). Mokyr et al. (2015) demonstrate that the 'technology anxiety' reflected in these statements has emerged repeatedly - mainly at times of rapid technological change and/or deep economic recessions. At other times, both economists and policy-makers have taken the view that job losses caused by technological change are temporary and would be reversed as a wide range of compensation mechanisms trigger new demand for labour.

Yet the multiplicity of the compensation mechanisms (e.g., occupational reallocation, lower product prices, output expansion, higher investment, etc.) has made it difficult to derive noncontingent conclusions. As Vivarelli (2014) has indicated, the compensation mechanisms require strict assumptions, overlook the secondary adverse demand effects that may result from falling wages, and may not all work in tandem. Therefore, Vivarelli (2014: 121) argue that "...economic theory does not have a clear-cut answer regarding the employment effect of innovation.” Therefore, attention should “... focus on aggregate, sectoral, and microeconomic empirical analyses that take into account the different forms of technical change ... the various compensation mechanisms and the possible hindrances they face."

The call for empirical research is justified, but the empirical evidence has also proved inconclusive. Even though a negative relationship between technological innovation and employment cannot be established, the positive relationship tend to be reported when R\&D and/or product innovation ${ }^{1}$ are used as proxies for technological change and when the estimations are based on high-tech industry/firm data (Vivarelli, 2014). In contrast, process innovation is reported to have a negative effect on employment and the adverse effect may be exacerbated as trade openness increases (Spiezia et al., 2002; Piva, 2003; Pianta, 2004). A third conclusion is that labour market flexibility and higher levels of product-market competition are usually associated with positive or less adverse innovation effects on employment (See also Benavente and Rodolfo, 2008). Finally, technological innovation may be skill-biased, with job 
creation for skilled labour being at the expense of job destruction for unskilled labour (Berman et al., 1998; Machin, 2001).

Chennells and van Reenen (2002) draw attention to methodological issues as additional sources of heterogeneity in the evidence base. For example, a positive effect-size estimates are more likely to be reported when primary studies use cross-section data. However, such estimates may be biased due to correlated fixed effects. Furthermore, the choice of technological innovation may be endogenous to changes in skill supply or changes in labour-market institutions. The use of time-differenced data may eliminate the fixed effects, but it may also exacerbate the measurement problems and lead to downward bias in estimated parameters, which is more prevalent when differencing is based on short time periods such as subsequent years (Draca et al., 2007).

As technological change is un-observable, Chennells and van Reenen (2002) also draw attention to measurement issues that arise when researchers use various innovation proxies such as research and development (R\&D) investment, ICT (information and telecommunications technology) investment, intellectual property assets (IPAs) consisting of patents and trademarks, or knowledge spillovers captured by knowledge capital pools at the industry, regional or national levels. Whereas $R \& D$ investment has the advantage of being measured by a comparable unit of account (currency), the effect-size estimates based on this measure may be biased due to existence of spillover effects. On the other hand, knowledge spillovers may allow for capturing technology diffusion but they are difficult to measure and the lag-structure in the relationship between spillovers and employment is not known. ${ }^{2}$

The brief summary above indicates that the effect of technological innovation on total employment or on employment of skilled, mix-skills and unskilled labour is likely to be highly heterogeneous. Of the sources of heterogeneity, product innovation is expected to have a positive employment effects in contrast to process innovation. Secondly, the positive effect on total demand for labour may conceal a negative effect on the demand for unskilled labour. Third, the reported effect-size estimates are vulnerable to imperfections in the measurement of technological innovation. Finally, the effect-size estimates are likely to be contaminated with biases due to correlated fixed effects or endogeneity in the relationship between technological innovation and employment. 
Although the existing reviews provide informative and valuable insights, they leave a number of issues unresolved. Existing reviews are silent on selection bias that, if exists, leads to truncated samples that, in turn, leads to distorted averages and confidence intervals for effectsize estimates (Doucouliagos and Laroche, 2009). Reviewers acknowledge the sources of heterogeneity but they neither provide quantitative estimates for its incidence nor do they discuss the extent to which it can be explained by moderating factors that capture its sources. Third, the existing reviews do not address between- and within-study data dependence, which is a major concern in the synthesis of research evidence based on observational data. Finally, and in spite of the theoretical predictions about the mediating roles of the labour-market flexibility and product-market competition, the existing reviews do not provide a systematic evaluation of how effect-size estimates based on data from different OECD countries relate to labour- and product-market institutions in those countries. We address these issues and gaps in the knowledge base by drawing on bivariate and multivariate meta-regression techniques.

\section{The derived labour demand model}

This meta-analysis is based on primary studies that estimate various specifications of the socalled derived labour demand model (DLDM). Following Van Reenen (1997) and Chennells and van Reenen (2002), a fully-specified industry-level DLDM can be written as follows:

$\log L=(\sigma-1) \log (A / B)-\sigma \log (W / P)+\log K+\sigma \log R$

Replacing the unobserved technology variables $(A$ and $B)$ with an appropriate measure of innovation, and assuming that the cost of capital is constant across industries but varies over time, the stochastic version of the DLDM can be written as:

$\log L_{i t}=\gamma \log (\text { Tech_Innov })_{i t}+\beta_{1} \log (W / P)_{i t}+\beta_{2} \log K_{i t}+\tau_{t}+\varepsilon_{i t}$

where $i$ is industry; $\tau_{t}$ is a set of time dummies that capture the cost of capital over time; $\varepsilon_{i t}$ is a white noise error term; $\beta_{1}$ is the elasticity of substitution between capital and labour in response to change in real wages; and Tech_Innov is an innovation measure (e.g., R\&D intensity, patent or trade-mark counts, ICT, knowledge spillovers, etc.) that proxies for technological change. 
Equation (2) is an industry-level DLDM, but it can also be used for estimations with firm-level data. The difference between industry- and firm-level estimates depends on whether technological diffusion is immediate and whether innovation by a given firm has a strong creative destruction effect on its competitors. If diffusion is slow and the creative destruction effect is strong (i.e., if innovation by a given firm renders the technology of its competitors obsolete at fast rates), the firm level estimates of the innovation-employment relationship can be expected to be larger than industry-level estimates. This is because the innovative firm will enjoy increased market share and hence its demand for labour will be higher for a given increase in innovation.

Drawing on Chennells and van Reenen (2002) and other reviews, the theoretical predictions from the model can be stated as follows:

1. The higher is the firm's market power, the less likely it is to observe a positive relationship between technological innovation and employment. This is because firms with high market power will set prices above marginal costs, depressing the level of demand for products/services and hence the level of demand for labour.

2. Stronger employment protection legislation (EPL) and/or more rigid product-market regulation $(P M R)$ are more likely to be associated with negative effects of technological innovation on employment - mainly due to reduced competition and flexibility in the product and labour markets respectively.

3. However, the positive effect in (2) may be dampened or reversed if high levels of product-market competition reduce job security and the workers demand higher wages to compensate for the latter (Amable and Gatti, 2004).

4. The higher the rate of substitution between capital and labour is, the more likely it is to observe a negative relationship between technological innovation and employment.

5. The relationship between technological innovation and employment at the firm level is more likely to be positive if innovation does not diffuse immediately and the innovative firm increases its market share at the expense of its competitors. 
6. Process innovation is associated with reduced demand for labour whereas product innovation is more likely to be associated with output expansion and hence higher demand for labour.

In the meta-regression analysis, we will include empirical studies that draw on: (i) a complete version of the DLDM specified above; (ii) an uncompensated labour-demand version where at least wages and technological innovation are controlled for (van Reenen, 1997); or (iii) any variant in between where capital or output is controlled for. One aim of this study is to establish where the balance of the evidence lies and whether the synthesized evidence conforms to narrative review conclusions and predictions from the DLDM. Another aim is to test whether the existing 'effect-size' estimates vary between different model specifications, estimation techniques, sample characteristics, and other moderating factors.

Given our focus on DLDM studies, we exclude studies using a variant of the skill/wage share or innovation-decomposition models. Skill/wage share models yield estimates that measure the effect of innovation on the share of skilled (unskilled) labour in total wage bill or in total employment (Berman et al, 1994 and 1998; Antonioli et al., 2011; Xu and Li, 2008). This is in contrast to DLDM studies, which report the effect of innovation on the demand for total, skilled or unskilled labour. The innovation-decomposition model (Harrison et al., 2008 and 2014; Hall et al., 2008; Benavente and Lauterbach, 2008) allows for estimating effects on the demand for labour but it measures innovation differently than the DLDM. Whilst process innovation is usually a binary variable, product innovation is measured by the number of new products introduced. Studies informed by this model are excluded because the dichotomous proxy for process innovation (whether the firm introduces process innovation or not) has limited informational content and the proxy for product innovation (number of 'new products' introduced) may reflect innovation, strategic competition or both. These differences, their sources and their implications for our inclusion/exclusion decisions are discussed in detail in Part 1 of the Appendix. ${ }^{3}$

\section{Systematic review rules and overview of the research field}


In this systematic review, we follow the best-practice recommendations in Stanley et al. (2013) with respect to literature search, study inclusion and exclusion decisions, and data extraction. We have conducted title and abstract searches in eight electronic databases, using 21 key search terms and their extensions. The search was restricted to the period 1980-2013. The initial year is chosen on the basis of information from existing reviews, in which included empirical studies published before 1980 do not feature. The final year was determined by the start of the research project in the last quarter of 2013. Although we restricted the search to studies published in English, we did not impose any restriction on the country of origin for the data.

Studies informed by skill/wage share or innovation-decomposition models are excluded for reasons indicated above and discussed further in Part1 of the Appendix. We have also excluded a handful of studies that provide useful/innovative insights on technical competitiveness and cost competitiveness or much needed information on under-studied countries such as India. Some of these are excluded because they occupy a mid-ground position between the innovation decomposition model and the DLDM by controlling for different technological competitiveness measures in the same estimation (Bpgliacino and Pianta, 2010). Some are excluded because they are published after the cut-off date of 2013 for this study (e.g., Ciriaci et al., 2016; Mitra and Jha, 2015). Some others (Piva and Vivarelli, 2004b) draw on the same dataset as Piva and Vivarelli, (2005): an Italian firm-level database derived from questionnaire surveys commissioned by the investment bank Mediocredito Centrale (MCC) from 1992-1997. Given that the former is included in our sample, the latter has been excluded.

Two independent reviewers read the titles and abstracts of all studies captured in the electronic searches, using a range of first-stage inclusion criteria designed to ascertain if the study: (i) investigates the effect of technological innovation however measured on employment of skilled, unskilled or mix-skills labour; (ii) has an empirical dimension as opposed to a theoretical focus only; and (iii) is NOT a review only. In the second stage, again two independent reviewers read the full text of the included studies and used second-stage inclusion criteria. The latter are designed to ensure that the included study: (i) draws on a variant of the DLDM as opposed to wage/skill share models or innovation decomposition models; (ii) discusses and documents the data used; (iii) discusses and documents the estimation methodology in the light of theoretical and econometric literature; and (iv) reports 'effect-size' estimates together with standard errors or $\mathrm{t}$-values and associated sample sizes. The process led to inclusion of 27 primary studies. The 
number eventually increased to 35 as a result of discovering new studies through snowballing and manual search.

We extracted all 'effect-size' estimates (570 in total) reported in 35 primary studies, coding each estimate with respect to: (i) Publication type (journal article, working paper, book chapter, etc.) and date; (ii) model specification (full/uncompensated DLDM, differenced or level specification, inclusion of time/industry dummies, etc.); (iii) sample characteristics (country of origin for the data, firm/industry data, high/low/mixed levels of innovation intensity, panel/cross-section data, small/large firms, etc.); and (iv) estimation methods (OLS, Fixed effect or within estimators, and instrumental variable estimators such as GMM, 2SLS or 3SLS). We included all reported estimates for two reasons: ${ }^{4}$ (i) to make full use of existing information; and (ii) to avoid the risk of aggravating the selection problem that may exist at the primarystudy level with an additional sample selection problem that arises when reviewers rely on estimates that they or primary-study authors consider as 'preferred'.

Given that the unit of measurement for the dependent and independent variables differs within and between studies, we calculate partial correlation coefficients (PCCs) to ensure that the estimates are comparable. The PCC and its standard errors are calculated in accordance with (3) below, where $t_{i}$ and $d f_{i}$ are the t-values and degrees of freedom reported in primary studies.

$p c c_{i}=t_{i} / \sqrt{t_{i}^{2}+d f_{i}^{2}} \quad$ and $\quad \operatorname{se\_ }_{-} p c c_{i}=\sqrt{\left(1-p c c_{i}^{2}\right) / d f_{i}}$

The PCC measures the strength of the association between technological innovation and employment - after controlling for other determinants of the demand for labour in the DLDM. Its standard error represents variations due to sampling error. Doucouliagos (2011) suggests that a partial correlation that is less than \pm 0.07 can be regarded as small, even if it is statistically significant. The partial correlation indicates strong association (large effect) if it is greater than \pm 0.33 , whilst a PCC in between indicates moderate effect. ${ }^{5}$

Table A1 in the Appendix provides an overview of the included studies, with information on a range of study characteristics. The majority of the primary studies included in this metaanalysis are published journal articles (71\%), followed by working papers (26\%). $74 \%$ of the 
studies utilised firm-level data, $14 \%$ utilised industry-level data, and the remainder utilised sector-level data.

The number of estimates reported in primary studies varies between 2 and 105. Median values of the within-study estimates are all positive except for three studies (Piva and Vivarelli, 2004a; Rottmann and Ruschinski, 1998; Yochum and Rhiel, 1990). The median estimate and t-value for the 'effect-size' estimates in the sample are 0.036 and 1.850, respectively. This summary points out to positive and significant median estimates, but the latter vary considerably between studies. The median estimates in firm-level studies vary between -0.017 (Piva and Vivarelli, 2004a) and 0.155 (Westermann and Schaeffer, 2001). In industry-level studies/estimations, the estimates vary between -0.550 (Yochum and Rhiel, 1990) and 0.257 (Berndt et al., 1992). Finally, the sector-level estimates vary between 0.062 (Luchesse and Pianta, 2012) and 0.242 (Mastrostefano and Pianta, 2009).

Funnel graphs in Figure 1 provide more information about the extent of heterogeneity and the risk of publication selection bias. The graphs are based on six evidence pools, distinguished by different combinations of innovation and skill types for which evidence exists. The mean-effect (represented by the vertical line) is positive in all evidence pools, with the exception of evidence pool (4) that reflect the estimates for unskilled labour demand. The distribution of the estimates around the vertical line indicates a moderate positive selection bias in graphs (3) to (6). This is evident from the relatively larger number of estimates above the mean compared to those below the mean. The two exceptions are evidence pools (1) and (2).

In evidence pool (1), there is an indication of a strong negative selection bias with respect to process innovation, whereas in (2) we observe evidence of strong positive selection bias with respect to product innovation. These visual indicators will be tested formally through metaregression below. If confirmed, they indicate that summary measures or vote-counting results cannot be relied upon for correct inference about the effects of technological innovation on employment.

Moreover, a significant number of estimates are beyond the $95 \%$ pseudo confidence intervals - indicating heterogeneity that cannot be explained by sampling errors (Sterne and Harbord, 2004). Using the random-effect meta-regression estimator proposed by Harbord and Higgins (2008), we find that residual heterogeneity that cannot be explained by sampling differences is 
excessive ( $75 \%$ and over) in three evidence pools $(3,56)$, but it is moderate or low in evidence pools (1, 2 and 4). 
Figure 1: Funnel plots - potential selection bias and heterogeneity ${ }^{6}$
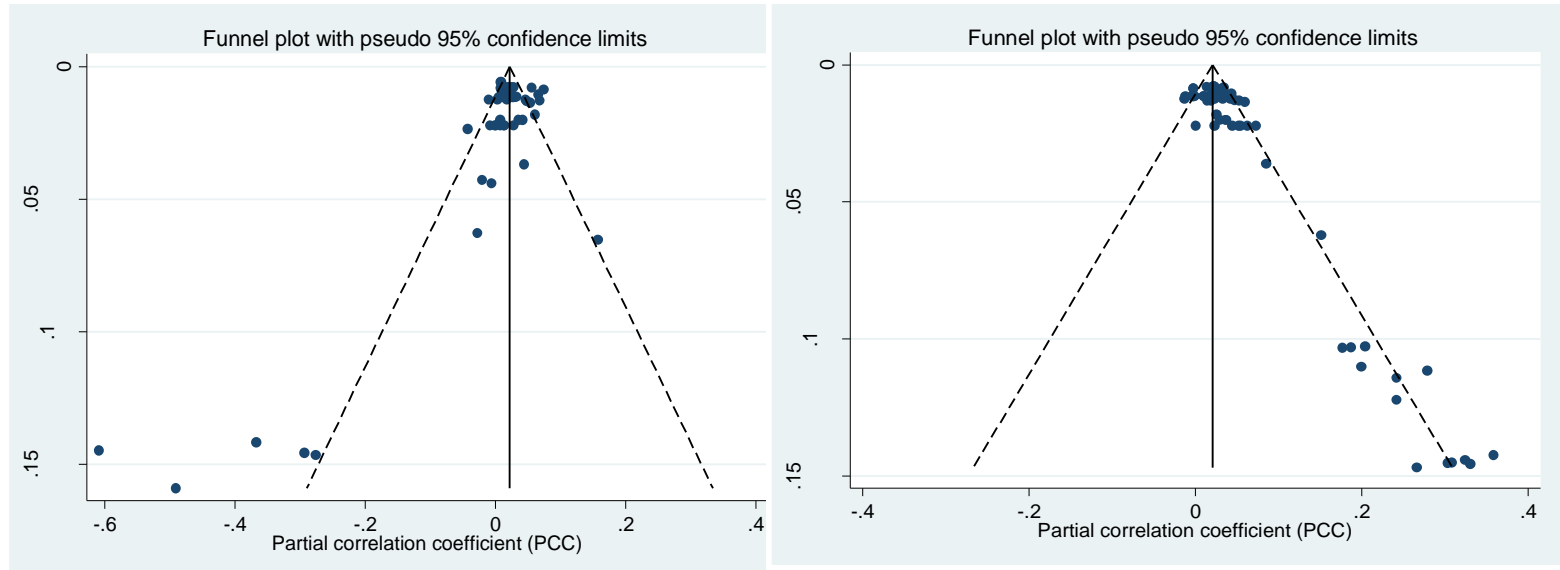

1. Process innovation and mixed-skills labour. Heterogeneity: $68 \%$

2. Product innovation and mixed-skills labour Heterogeneity: $29 \%$

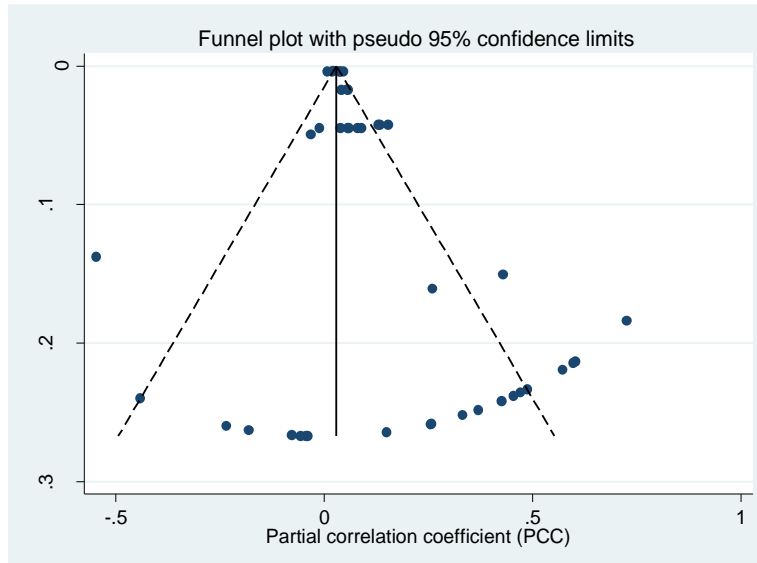

3. Undifferentiated innovation and skilled labour Heterogeneity: $75 \%$

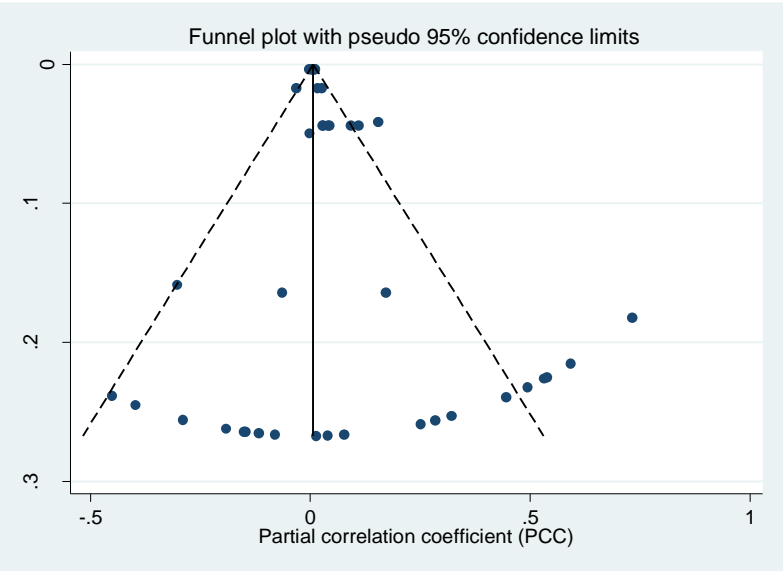

4. Undifferentiated innovation and unskilled labour Heterogeneity: $59 \%$
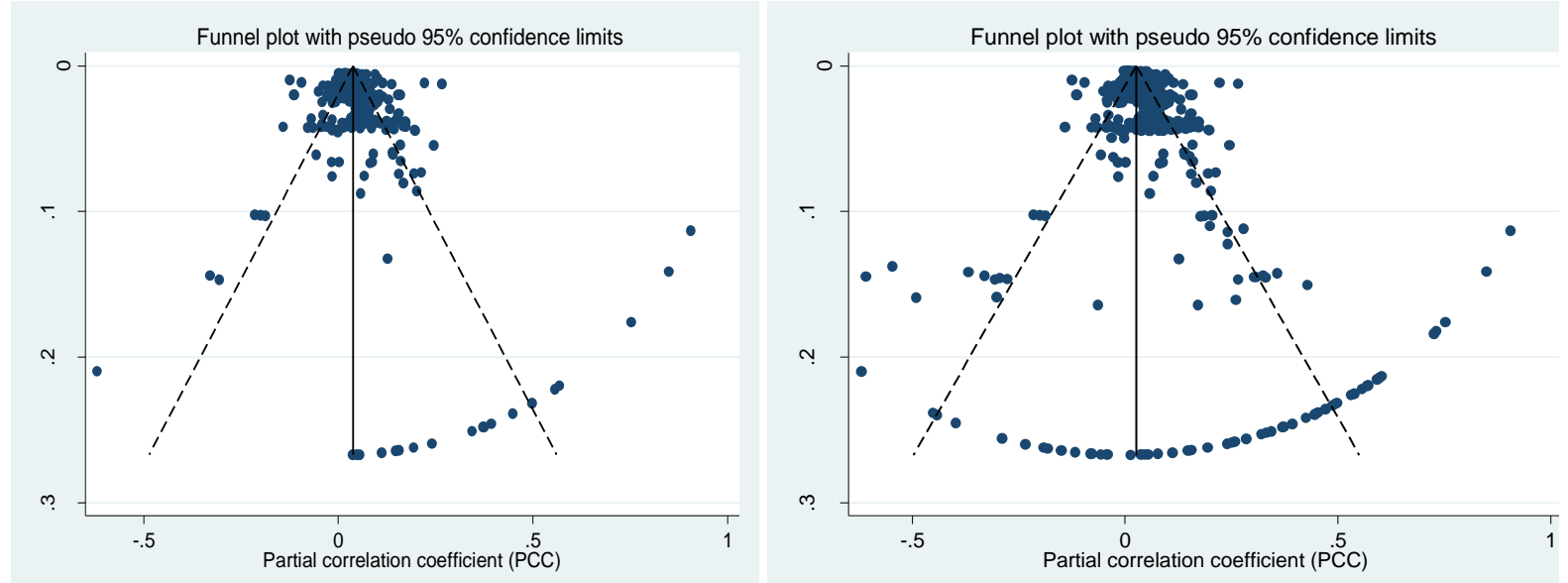

5. Undifferentiated innovation and mixed-skills Heterogeneity: $88 \%$

6. Full sample

Heterogeneity: 85\% 


\section{Why hierarchical meta-regression?}

Given the presence of heterogeneity, summary measures (particularly those that conceal a high level of heterogeneity) cannot be generalised to other contexts. In addition, summary measures that ignore the risk of selection bias can lead to incorrect inference in narrative reviews. That is why we conduct meta-regression analysis to quantify the sources of heterogeneity and take account of selection bias.

Our methodology is informed by Stanley $(2005,2008)$ and Stanley and Doucouliagos (2012). The underpinning theoretical framework is that of Egger et al. (1997), who postulate that researchers search across model specifications, econometric techniques and data measures to find sufficiently large (hence statistically-significant) effect-size estimates. This postulate implies that reported estimates are correlated with their standard errors. Denoting the effect size with $e_{i}$ and the standard error with $S E_{i}$, and assuming that the error term $\left(u_{i}\right)$ is independently and identically distributed (i.i.d.), the selection process can be stated as follows:

$p c c_{i}=\beta+\alpha s e_{\_} p c c_{i}+u_{i}$

However, model (4a) raises four estimation issues. First, the model is heteroskedastic because effect-size estimates have widely-different standard errors. To address this issue, we estimate a weighted least squares (WLS) version of (4a), where precision-squared (1/se_pcc $\left.c_{i}^{2}\right)$ is used as weights. This is equivalent to dividing both sides of (4a) with the standard error (Stanley and Doucouliagos, 2014 and 2012; Stanley, 2008), leading to:

$t_{i}=\alpha+\beta\left(1 / s_{-} p c c_{i}\right)+v_{i}$

Here $t_{i}$ is the t-value associated with the reported estimate and the error term $v_{i}$ is the error term in (4a) divided with the standard error. Model (4b) yields minimum-variance linear unbiased estimates if the Gauss-Markov conditions are satisfied. Testing for $\alpha=0$ is a test for publication selection bias or funnel asymmetry test (FAT), whereas testing for $\beta=0$ is a 'genuine effect' test or precision-effect test (PET) after controlling for selection bias. The latter is considered as substantial if $|\alpha| \geq 1$ or as severe if $|\alpha| \geq 2$ (Doucouliagos and Stanley, 2009; 
2012). Testing for selection bias is justified given the evidence about its prevalence in both social-scientific and medical research (Card and Krueger, 1995; Dickersin and Min, 1993; Ioannidis, 2005; and Simmons et al., 2011). ${ }^{7}$

The second issue in estimating the Egger model is that the relationship between primary-study estimates and their standard errors may be non-linear. Indeed, Stanley and Doucouliagos (2014) provide evidence that a quadratic specification is superior if the PET rejects the null hypothesis of zero effect. Then, the specifications of the non-linear Egger model (5a) and its WLS equivalent (5b) are:

$p c c_{i}=\gamma+\delta s e_{-} p c c_{i}^{2}+\omega_{i}$

$t_{i}=\gamma\left(1 / s e_{\_} p c c_{i}\right)+\delta s e_{-} p c c_{i}+\theta_{i}$

Model (5b) is estimated without a constant term and only if genuine effect is established beyond selection bias. It is referred to as precision-effect test corrected for standard errors (PEESE).

The third issue is about which estimator is better-suited for the data at hand. Many metaanalysis studies tend to estimate ( $4 \mathrm{~b}$ and/or $5 \mathrm{~b}$ ) with ordinary least squares (OLS), which is equivalent to estimating models ( $4 \mathrm{a}$ and/or $5 \mathrm{a}$ ) with a WLS statistical package that uses $1 / S E^{2}$ as weights. However, standard WLS would yield biased estimates in the presence of data dependence, which arises when a primary study using a particular dataset report multiple estimates or when different studies use overlapping datasets (Doucouliagos and Laroche, 2009). Data dependence may be an issue here because most studies report multiple estimates and some also use datasets from the same country of origin with different or overlapping time periods (see Table A1 in the Appendix).

Such sources of within- and between-study dependence can be taken into account by: (i) obtaining bootstrapped standard errors; (ii) conducting clustered data analysis; and (iii) using hierarchical models (Doucouliagos and Laroche, 2009). The first two methods correct the standard errors for within-study dependence but without modeling the sources of within- or between-study dependence explicitly. Stated differently, the first two methods may correct for standard errors but they may suffer from model misspecification bias if within- and/or betweenstudy dependence exists. 
Snijder and Bosker (2012) draw attention to additional sources of bias when standard nonhierarchical estimators is used (with or without clustering) in the presence of dependence. First, the sample size is exaggerated dramatically when the primary-study estimates are treated as independent despite evidence of between- or within-study dependence. Secondly, and irrespective of the sample size, there is a high risk of committing type-I error (i.e., rejecting the null hypothesis when the latter is true) if there is between-study dependence. If within-study dependence exists, the precision-effect test (PET) would be too conservative - i.e., the type-I error probability would be too low.

Third, clustered-data estimations are robust but inefficient. They work well if the sample includes 30 or more studies and if the number of 'effect-size' estimates per study are similar in number - which is rarely the case. Fourth, HMs allow for quantifying the level of intra-study correlation (ISC) - i.e., the extent of within-study dependence - in addition to variances of the between-study and/or within-study random-effect components. The larger is the ISC, the more severe is the risk of biased estimates or summary measures.

One drawback of the HMs is that they assume normality of the model residuals. This assumption is more explicit in HMs compared to standard WLS. However, violation of the normality assumption affects the confidence intervals (or the p-values) - not the coefficient estimates. We take account of this issue by estimating the HMs with heteroskedastic standard errors at two higher-level clusters: skill and innovation types. We base our conclusions on the estimation with smallest log-likelihood value in magnitude. Therefore, we are of the view that HMs, if justified by LR tests, address a wide range of estimation issues with little or no cost for consistency and/or correct inference (Demidenko, 2004; McCulloch et al., 2008; Snijder and Bosker, 2012).

In building our HMs, we nest the primary studies (lower-level groups) within six higher-level groups that correspond to unique pairs of innovation and skill types. ${ }^{8}$ We also allow for random variation in the effect-size estimates due to random intercepts (RI) or random intercepts and slopes (RIS). The choice between OLS and HM; and between the RI and RIS specifications is based on likelihood ratio (LR) tests, with the null hypothesis that the compared model is nested within the preferred HM. ${ }^{9}$ The RI and RIS specifications of the PET-FAT and PEESE models are given in Part 2 of the Appendix. 
The final issue is that some studies report disproportionately large numbers of estimates compared to the rest. For example, four studies (van Reenen, 1997; Berndt et al., 1992; Lachenmaier and Rottmann, 2011; and Yang and Lin, 2008) account for 43\% of the total estimates in the evidence pool. Even though the HM takes account of between- and withinstudy dependence, the sheer number of estimates reported by such studies may dominate the informational content of the evidence base and the meta-regression estimates. Therefore, we estimate all meta-regression models by also weighting the estimates with the inverse of the number of estimates reported by each study. This weighting scheme ensures that the weight of each study in the sample is equal to one.

The 'average' employment effect in the bivariate meta-regression is more reliable than other summary measures that do not account for selection bias. However, its out-of-sample generalizability may be limited due to excessive heterogeneity. Therefore, we obtain quantitative measures of heterogeneity using a random-effect meta-regression model proposed by Harbord and Higgins (2008). Then we verify the sources of heterogeneity by augmenting bivariate meta-regression model with a range of dummy variables $(Z)$ that capture the dimensions of the research field. The random-intercepts-only (RI) and random-intercepts-andslopes (RIS) specifications of the multivariate meta-regression model (MVMRM) are given in Part 2 in the Appendix.

We estimate the PET/FAT/PEESE models for 5 sub-samples of paired innovation and skill types and for the full sample. Table 1 reports the results together with model diagnostics such as LR test statistics, log-likelihood values for hierarchical and the comparator models, variance inflation factors, levels of heterogeneity, and intra-study correlation (ISC). The MVMRM is estimated with the full sample, controlling for skill and innovation types as additional sources of heterogeneity. To avoid multicollinearity and overfitting, we follow a general-to-specific model-estimation routine; and present the general model results in Table A4 in the Appendix. The specific model is obtained by omitting the most insignificant covariates (those with the largest $\mathrm{p}$-value) one at a time until all remaining covariates are statistically significant. Results from the specific model are presented in Table 2 in the main text. 


\section{Hierarchical meta-regression results}

Table 1 consists of two panels. In panel A, we present the PET/FAT results for the level of selection bias $(\alpha)$ and for the 'effect-size' estimates $(\beta)$ after controlling for selection bias. Columns A1 to A3 and A6 report HM estimation results based on HM specifications justified by LR tests. In columns A4 and A5, we use standard WLS as the latter is justified by LR tests. LR test Chi-square and log-likelihood values justify the HM specification where used. Finally, the robustness of the results to equal study weights is checked and the results, which are consistent with Table 1, are reported in Table A3 in the Appendix.

Before discussing the findings in Table 1, we would like to draw attention to two pieces information that HMs provide: (i) the variances of the random-effect components (not reported here to save space but available on request); and (ii) the intra-study correlation (ISC) results at the bottom of the table. The variances of the random-effect components are significantly different than zero and indicate the presence of random effects at the study level - which reflect study-specific random intercepts. However, random effects at the higher level (innovation and skill type pairs) in the full sample (A6 and B6), are either small or insignificant. Finally, the estimated variances also indicate the presence of random slopes where the latter are justified by LR tests.

On the other hand, the ISCs indicate the presence of dependence between primary-study estimates, which ranges from 0.121 - 0.731 . These magnitudes indicate moderate to strong intra-study dependence or "social grouping", which the HMs take into account explicitly (Snijder and Bosker, 2012). The research and practice implication of these findings is that it is highly advisable to model within- and between-study dependence explicitly and use the wide range of diagnostics that HM estimators allow for so that the meta-regression model is specified correctly and the correct estimator is made.

Other findings in Table 1 indicate that selection bias is moderate or insignificant in four evidence clusters (A3 to A6), but substantial in two clusters (A1 and A2). In the latter, the bias is negative in A1 (process innovation and demand for mixed-skills labour) but positive in A2 (product innovation and demand for mixed-skills labour). This finding confirms the visual story in the funnel plots - and is consistent with the suspicion that some researchers report selectively those empirical results that are statistically significant in the 'right' direction. In other words, 
there is a preponderance of confirmatory estimates that support the theoretical predictions process innovation has a negative effect on employment whereas product innovation has a positive effect (Katsoulacos, 1984; Harrison et al, 2008; 2014) ${ }^{10}$. This finding demonstrates that the theory-congruent conclusions reported in narrative reviews may be misleading as they are based on highly-selected evidence.

Effect-size estimates for process and product innovation demonstrate that this is the case. For process innovation (A1), the average effect size is positive (0.029) and significant. The estimate remains significant in B1 where we also control for quadratic relationship between primarystudy estimates and their standard errors. In contrast, the average effect size for product innovation (A2) is insignificant! This is because the risk of selection bias in this evidence pool is the highest ( $\alpha=1.895$ ), and unsurprisingly, the effect-size estimate becomes insignificant when selection bias is taken into account.

Consistent (PEESE) 'effect-size' estimates $(\gamma)$ in Panel B of Table 1 should be considered as small because they fall below the benchmark of 0.07 suggested by Doucouliagos, (2011) and the earlier benchmark of 0.10 suggested by Cohen (1988). Given the confidence interval around the point estimates, the small but positive effect of technological innovation on the demand for labour may well be practically insignificant. This is irrespective of the evidence pool one focuses on.

Furthermore, the results in Panel B lend some support to the skill-biased technological change hypothesis in that the positive effect on skilled labour demand (0.029 in B4) is larger than unskilled labour (0.007 in B5). However, it must also be noted that the effect on skilled-labour demand is smaller than the effect on mixed-skills labour (0.039 in B3). This anomaly reflects the relatively higher level of positive selection in the evidence pool for skilled-labour demand (0.937 in A4) compared to mixed-skills labour demand (insignificant in A3). Hence, we conclude that more but less-selected evidence from DLDM estimations is required to ascertain the extent of skill-biased technical change. 
Table 1: Technological innovation and employment: Effect-size estimates by innovation and skill type

\begin{tabular}{|c|c|c|c|c|c|c|c|c|c|c|c|}
\hline \multirow[b]{2}{*}{ Dependent variable: $t$-value } & \multicolumn{6}{|c|}{ Panel A: PET/FAT } & \multicolumn{5}{|c|}{ Panel B: PEESE } \\
\hline & (A1) & (A2) & (A3) & (A4) & (A5) & (A6) & (B1) & (B3) & (B4) & (B5) & (B6) \\
\hline \multirow[t]{2}{*}{$\beta$ (in PET/FAT); $\gamma$ (in PEESE) } & $0.029 * * *$ & 0.004 & $0.037 * * *$ & $0.025 * * *$ & $0.004 *$ & $0.025 * * *$ & $0.027 * * *$ & $0.039 * * *$ & $0.029 * * *$ & $0.007 * * *$ & $0.028 * * *$ \\
\hline & $(0.008)$ & $(0.004)$ & $(0.007)$ & $(0.006)$ & $(0.002)$ & $(0.006)$ & $(0.007)$ & $(0.006)$ & $(0.005)$ & $(0.002)$ & $(0.005)$ \\
\hline \multirow[t]{2}{*}{$\alpha$} & $-1.405^{* *}$ & $1.895 * * *$ & 0.210 & $0.937 * * *$ & $0.712 * *$ & 0.461 & & & & & \\
\hline & $(0.683)$ & $(0.141)$ & $(0.378)$ & $(0.298)$ & $(0.287)$ & $(0.392)$ & & & & & \\
\hline \multirow[t]{2}{*}{ Std. error } & & & & & & & $-17.959 * * *$ & $-9.073 * * *$ & $3.531 * *$ & 2.053 & -1.187 \\
\hline & & & & & & & $(3.407)$ & $(1.997)$ & $(1.380)$ & $(1.289)$ & $(2.090)$ \\
\hline Obse & 66 & 69 & 344 & 42 & 43 & 567 & 66 & 344 & 42 & 43 & 567 \\
\hline Studies & 14 & 13 & 21 & 7 & 7 & 35 & 14 & 21 & 7 & 7 & 35 \\
\hline LR Test chi ${ }^{2}$ & 11.927 & 0.719 & 22.317 & 231.916 & 2.765 & 20.420 & 27.83 & 47.714 & 372.342 & 10.633 & 33.207 \\
\hline $\mathrm{P}>\mathrm{chi}^{2}$ & 0.000 & 0.397 & 0.000 & 0.000 & 0.096 & 0.000 & 0.000 & 0.000 & 0.000 & 0.005 & 0.000 \\
\hline Log-likelihood (HM) & -107.500 & -105.052 & -825.242 & -87.664 & -79.054 & -1289.587 & -109.829 & -825.802 & -89.189 & -81.236 & -1290.414 \\
\hline Log-likelihood (Comp. model) & -130.225 & -108.570 & -848.867 & N.A. & N.A. & -1348.930 & -125.722 & -849.161 & N.A. & N.A. & -1359.481 \\
\hline Heterogeneity & $68 \%$ & $29 \%$ & $88 \%$ & $75 \%$ & $59 \%$ & $85 \%$ & N.A. & N.A. & N.A. & N.A. & N.A. \\
\hline Estimator & HM2/RI & HM2/RI & $\mathrm{HM} 2 / \mathrm{RI}$ & WLS & WLS & HM3/RIS & HM2/RI & HM2/RI & WLS & WLS & HM3/RIS \\
\hline Within-study correlation (ICC) & $0.573 * * *$ & $0.210 * * *$ & $0.38 * * *$ & N.A. & N.A. & $0.121 *$ & $0.731 * * *$ & $0.439 * * *$ & N.A. & N.A. & $0.186^{* *}$ \\
\hline
\end{tabular}

Notes: Samples: A1 \& B1 - process innovation and demand for mixed-skills labour; A2 - product innovation and demand for mixed-skills labour; A3 \& B3 - undifferentiated innovation and demand for mixed-skills labour; A4 \& B4 - undifferentiated innovation and skilled labour; A5 \& B5 - undifferentiated innovation and demand for unskilled labour; A6 \& B6 - full sample. Estimators: WLS - weighted least squares; HM2/RI - two-level hierarchical estimation with random intercepts; HM2/RIS - two-level hierarchical estimation with random intercepts and slopes; HM3/RIS - three-level hierarchical estimation with random intercepts and slopes. Robust standard errors (in brackets) are clustered at the study level. Three observations with undue influence are excluded, using the DFBETA influence statistics. \# indicates the proportion of residual between-study variation due to heterogeneity, as opposed to within-study sampling variability. *, **, *** indicate significance at $10 \%, 5 \%$ and $1 \%$, respectively. N.A.: Not applicable. 
Finally, the evidence in Table 1 also points out a trade-off between selection bias and residual heterogeneity. The latter is higher (between 75\% - 88\%) when selection bias is small or insignificant. On the other hand, when heterogeneity is low (between 29\% - 68\%), the selection bias is substantial (greater than one) in two out of three estimations. This evident trade-off indicates the need not only for less selected estimates, but also for better data quality and estimation methods that would reduce the level of residual heterogeneity in less-selected estimates. In what follows, we conduct multi-variate meta-regression analysis to shed light on the sources of heterogeneity listed in Table 2 .

We organise the potential sources of heterogeneity in four categories: (i) publication type/date to verify if journal articles and work published after 2000 report systematically different estimates; (ii) variations in DLDM specification to verify if econometric specifications matter; (iii) characteristics of the samples used in primary studies to verify if data type, innovation type and measure, skill type, and country of origin for the firm/industry data are conducive to different estimates; and (iv) estimation methods to verify if controlling for endogeneity and time-invariant fixed effects lead to different estimates. The covariates within each category are dummy variables that take the value of 1 if the primary-study estimate is associated with the controlled characteristic and zero if it is associated with the excluded characteristic(s). They are all interacted with precision to capture their effects on 'effect-size' estimates reported in primary studies.

Coefficients on the covariates should be interpreted as follows: a positive (negative) and significant coefficient indicates that primary-study estimates characterised by the control dummy are larger (smaller) than those associated with the reference category. A non-significant coefficient indicates no systematic difference between the primary-study estimates associated with the controlled and reference categories. The expected signs on the coefficients are informed by conclusions reported in the narrative reviews discussed above and by our reading of the studies included in the meta-analysis. 
Table 2: Sources of heterogeneity and expected effect sign

\begin{tabular}{|c|c|c|c|}
\hline $\begin{array}{l}\text { Sources of variation in the evidence } \\
\text { base }\end{array}$ & $\begin{array}{c}\text { Controlled } \\
\text { category }\end{array}$ & $\begin{array}{c}\text { Reference } \\
\text { category }\end{array}$ & $\begin{array}{l}\text { Expected } \\
\text { sign }\end{array}$ \\
\hline \multicolumn{4}{|l|}{ A. Publication type and date } \\
\hline $\begin{array}{l}\text { Journal article, working paper, book } \\
\text { chapter }\end{array}$ & Journal article & $\begin{array}{l}\text { Working paper, } \\
\text { book chapter }\end{array}$ & $+/-$ \\
\hline Publication date after 2000 & Yes & $\begin{array}{l}\text { Publications } 2000 \\
\text { and before }\end{array}$ & + \\
\hline \multicolumn{4}{|l|}{ B. Model specification } \\
\hline Informed by theoretical DLDM & Yes & Ad hoc DLDM & n.a. \\
\hline Dynamic specification & Yes & No & - \\
\hline Time dummies included & Yes & No & $+/-$ \\
\hline $\begin{array}{l}\text { Industry or sector dummies } \\
\text { included }\end{array}$ & Yes & No & - \\
\hline Wage included in model & Yes & No & n.a. \\
\hline Output included in model & Yes & No & n.a. \\
\hline Capital included in model & Yes & No & n.a. \\
\hline Long-term effect (3 lags or more) & Yes & No & - \\
\hline \multicolumn{4}{|l|}{ C. Sample characteristics } \\
\hline Panel data & Yes & $\begin{array}{l}\text { Cross-section, } \\
\text { time-series }\end{array}$ & - \\
\hline Industry or sector data & Yes & Firm & - \\
\hline Innovation measure: R\&D & & & + \\
\hline $\begin{array}{l}\text { Innovation measure: Intellectual } \\
\text { property assets (IPAs) }\end{array}$ & Yes & No & n.a. \\
\hline Innovation measure: ITC & Yes & No & $+/-$ \\
\hline Innovation measures: R\&D+IPA & Yes & No & n.a. \\
\hline Innovation type: Process & Yes & No & - \\
\hline Innovation type: Product & Yes & No & + \\
\hline $\begin{array}{l}\text { Newness of Innovation: First to } \\
\text { industry or country }\end{array}$ & Yes & First to firm & + \\
\hline Skill type: Unskilled labour & Yes & $\begin{array}{l}\text { Mixed skills and } \\
\text { skilled labour }\end{array}$ & - \\
\hline Sector: Manufacturing & Yes & Other sectors & $+/-$ \\
\hline $\begin{array}{l}\text { Country: Canada, France, Germany, } \\
\text { Italy, Netherlands, Norway, Spain, } \\
\text { Sweden, UK, USA, OECD } \\
\text { Countries }\end{array}$ & Yes & $\begin{array}{l}\text { Data from Non- } \\
\text { OECD countries } \\
\text { and other Country }\end{array}$ & n.a. \\
\hline High innovation intensity & Yes & No & + \\
\hline Firm size: Large & Yes & $\begin{array}{l}\text { Small and mixed- } \\
\text { size firms }\end{array}$ & $+/-$ \\
\hline \multicolumn{4}{|l|}{ D. Estimation method } \\
\hline GMM & Yes & OLS and all others & - \\
\hline Differenced / within & Yes & No & - \\
\hline
\end{tabular}

Estimation results from the general model (Table A4 in the Appendix) indicate that the moderating variables reduce the residual heterogeneity only marginally - from $85 \%$ in the fullsample bivariate model in Table 1 column A6 to $79 \%$ in general MVMRM in Table A4. 
Another observation is that the specification of the DLDM, the measure for innovation (with the exception of ICT and intellectual property assets), the country of origin for the data (with the exception of Canada and the US) are insignificant in explaining heterogeneity. Finally, the results indicate that the effects of innovation types (insignificant in the case of process innovation, negative and significant in the case of product innovation) are the opposite of what the theory predicts. However, we do not use the general model findings as a basis for inference as the coefficient estimates may be unstable due to multicollinearity, with a VIF value of 13.41.

Specific-model estimation results, presented in Table 3, are obtained by dropping the covariates with the largest $p$-value one at a time until all remaining covariates are significant. Then precision is added to the model to verify if the sign/significance of the covariates remain stable. Finally, to account for heteroscedasticity, the specific model is estimated with two different types of heteroskedastic residual-error structures at the innovation-type level (column 2) and at the skill-type level (column 3). Finally, we estimated the specific model by weighting the primary-study estimates with the inverse of the total number of estimates in each study (column 4).The preferred model is (4), given the lower magnitude of the log-likelihood value.

We derive two sets of conclusions from the results in Table 3: (a) conclusions supported by highly-consistent evidence (marked bold); and (b) conclusions supported by moderatelyconsistent evidence. The former depend on significance of the moderating factor in column (4) and sign/magnitude consistency with preceding columns. The latter depend on significance and sign/magnitude consistency across columns 1 to 3. 
Table 3: Sources of heterogeneity: Specific model estimations

\begin{tabular}{|c|c|c|c|c|}
\hline Dependent variable: $t$-value & (1) & (2) & (3) & (4) \\
\hline \multicolumn{5}{|l|}{ Publication type/year } \\
\hline \multirow[t]{2}{*}{ Precision } & 0.004 & 0.003 & 0.006 & 0.005 \\
\hline & $(0.013)$ & $(0.013)$ & $(0.012)$ & $(0.013)$ \\
\hline \multirow[t]{2}{*}{ Publication date after 2000} & $0.023 * * *$ & $0.023 * *$ & $0.020 * * *$ & $0.011 * *$ \\
\hline & $(0.009)$ & $(0.009)$ & $(0.007)$ & $(0.006)$ \\
\hline \multicolumn{5}{|l|}{ Model specification } \\
\hline \multirow{2}{*}{ Output included in model } & $-0.023 * * *$ & $-0.022 * * *$ & $-0.024 * * *$ & $-0.016 *$ \\
\hline & $(\mathbf{0 . 0 0 8 )}$ & $(\mathbf{0 . 0 0 8 )}$ & $(\mathbf{0 . 0 0 8 )}$ & $(\mathbf{0 . 0 0 9 )}$ \\
\hline \multirow[t]{2}{*}{ Long-term effect (3 yrs. or more) } & $-0.016 * * *$ & $-0.016 * * *$ & $-0.017 * * *$ & $-0.026 * * *$ \\
\hline & $(\mathbf{0 . 0 0 6})$ & $(0.006)$ & $(0.004)$ & $(\mathbf{0 . 0 0 5})$ \\
\hline \multicolumn{5}{|l|}{ Sample characteristics } \\
\hline \multirow{2}{*}{ Data type: Panel } & $-0.023 * *$ & $-0.023 * *$ & $-0.015^{*}$ & -0.004 \\
\hline & $(0.010)$ & $(0.010)$ & $(0.008)$ & $(0.010)$ \\
\hline \multirow{2}{*}{ Industry or sector data } & $0.039 * *$ & $0.036^{* *}$ & $0.030^{*}$ & 0.026 \\
\hline & $(0.017)$ & $(0.016)$ & $(0.018)$ & $(0.017)$ \\
\hline \multirow[t]{2}{*}{ Innovation measure: IPA } & $-0.010 * * *$ & $-0.009 * * *$ & $-0.010 * * *$ & $-0.009 * *$ \\
\hline & $(\mathbf{0 . 0 0 3 )}$ & $(\mathbf{0 . 0 0 3 )}$ & $(\mathbf{0 . 0 0 3 )}$ & $(0.004)$ \\
\hline \multirow[t]{2}{*}{ Innovation measure: ICT } & $0.114 * *$ & $0.106^{* *}$ & $0.116^{* *}$ & -0.020 \\
\hline & $(0.049)$ & $(0.042)$ & $(0.054)$ & $(0.109)$ \\
\hline \multirow[t]{2}{*}{ Skill type: Unskilled labour } & $-0.020 * * *$ & $-0.020 * * *$ & $-0.019 * * *$ & $-0.017 * * *$ \\
\hline & $(\mathbf{0 . 0 0 5 )}$ & $(\mathbf{0 . 0 0 5 )}$ & $(\mathbf{0 . 0 0 6 )}$ & $(\mathbf{0 . 0 0 4 )}$ \\
\hline \multirow{2}{*}{ Sector: Manufacturing } & $0.043 * * *$ & $0.043 * * *$ & $0.036 * * *$ & $0.023 * *$ \\
\hline & $(\mathbf{0 . 0 1 0})$ & $(\mathbf{0 . 0 1 0})$ & $(0.009)$ & $(\mathbf{0 . 0 1 1})$ \\
\hline \multirow[t]{2}{*}{ Canada data } & $-0.048 * *$ & $-0.049 * *$ & $-0.042 *$ & $-0.032 * *$ \\
\hline & $(\mathbf{0 . 0 2 1})$ & $(\mathbf{0 . 0 2 1})$ & $(0.023)$ & $(0.013)$ \\
\hline \multirow{2}{*}{ UK data } & $0.022^{*}$ & $0.023^{*}$ & 0.016 & 0.011 \\
\hline & $(0.013)$ & $(0.013)$ & $(0.013)$ & $(0.018)$ \\
\hline \multirow[t]{2}{*}{ US data } & $0.075 * * *$ & $0.075 * * *$ & $0.063 * * *$ & $0.058 * * *$ \\
\hline & $(\mathbf{0 . 0 1 4 )}$ & $(\mathbf{0 . 0 1 4 )}$ & $(\mathbf{0 . 0 1 4 )}$ & $(\mathbf{0 . 0 2 1})$ \\
\hline \multirow[t]{2}{*}{ OECD countries data } & $0.016 * * *$ & $0.015 * * *$ & $0.015 * *$ & $0.012 * * *$ \\
\hline & $(\mathbf{0 . 0 0 5 )}$ & $(\mathbf{0 . 0 0 5 )}$ & $(\mathbf{0 . 0 0 6 )}$ & $(0.004)$ \\
\hline \multirow[t]{2}{*}{ High innovation intensity } & $-0.035 * * *$ & $-0.035 * * *$ & $-0.027 * * *$ & $-0.029 * *$ \\
\hline & $(0.006)$ & $(0.006)$ & $(0.005)$ & $(0.013)$ \\
\hline \multicolumn{5}{|l|}{ Estimation method } \\
\hline \multirow[t]{2}{*}{ Differenced / within estimation } & $-0.012 * * *$ & $-0.011 * * *$ & $-0.011 * * *$ & $-0.009 *$ \\
\hline & $(\mathbf{0 . 0 0 3 )}$ & $(\mathbf{0 . 0 0 3 )}$ & $(\mathbf{0 . 0 0 3})$ & $(0.005)$ \\
\hline \multirow[t]{2}{*}{ Constant } & -0.151 & -0.138 & -0.037 & 0.599 \\
\hline & $(0.314)$ & $(0.307)$ & $(0.329)$ & $(0.483)$ \\
\hline Intra-study correlation & $0.256 * * *$ & N.A. & N.A. & N.A. \\
\hline Observations & 567 & 567 & 567 & 567 \\
\hline Studies & 35 & 35 & 35 & 35 \\
\hline LR Test chi ${ }^{2}$ & 215.618 & 216.082 & 216.077 & 4319.460 \\
\hline $\mathrm{P}>\mathrm{chi}^{2}$ & 0.000 & 0.000 & 0.000 & 0.000 \\
\hline Log-likelihood (HM) & -1221.714 & -1219.098 & -1176.717 & -80.321 \\
\hline Log-likelihood (Comp. model) & -1252.818 & N.A. & N.A. & N.A. \\
\hline VIF & 8.05 & 8.05 & 8.05 & 8.05 \\
\hline Heterogeneity\# & $80 \%$ & $80 \%$ & $80 \%$ & $80 \%$ \\
\hline Estimation & HM3/RI & HM3/RI & HM3/RI & HM3/RI \\
\hline
\end{tabular}

Notes: HM3/RI indicates three-level HM with random intercepts. \# the proportion of residual between-study variation due to heterogeneity. Homoscedastic residual-error structures (column 1); followed by heteroskedastic residual-error structures by skill type (column 2) and by innovation type (column 3). Column 4 reports estimates based on sampling weights defined as the inverse of the number estimates within each primary study. Three observations with undue influence are excluded, using the DFBETA influence statistics. *, **, *** indicate significance at $10 \%, 5 \%$ and $1 \%$, respectively. N.A.: mot available with heteroskedastic error structure. 
Findings supported by highly-consistent evidence are in partial agreement only with two narrative review conclusions. First, the effect of technological innovation on unskilled labour demand is smaller compared to the effect on skilled or mixed-skills labour demand. This is also in line with the skill bias reported in skill/wage share literature. Our contribution here is to combine both bivariate and multivariate meta-regression results and reveal that the effect on unskilled labour demand is positive but too small to be practically significant. Secondly, we confirm the conclusion in Vivarelli (2014) and report that primary studies published after 2000 tend to report relatively larger employment-effect estimates compared to previous studies.

However, our strongly-consistent findings are either incongruent with narrative review findings or shed new light on a number of moderating factors that they are unable to evaluate in a conclusive manner. For example, estimates based on high-innovation or high-tech firm/industry data in primary studies are relatively smaller than those associated with the reference category. This is in contrast to the conclusion in Vivarelli (2014). ${ }^{11}$ Secondly, we find no systematic difference between estimates based on process and product innovation data as both are insignificant in the specific MVMRM and their effects in the bivariate metaregression are the opposite of the consensus view. Third, the effect of technological innovation on labour demand is relatively smaller in the long run. This is in contrast to theoretical predictions that worker displacement in the short run may be reversed as compensation mechanisms trigger new demand for labour in the long run. However, this findings is in line with the creative destruction argument in Schumpeterian models, where firm/industry innovation becomes obsolete as competitors introduce new technology (Aghion et al., 2014).

Other strongly-consistent findings that shed new light on the role of the moderating factors can be listed as follows:

1. Inclusion of output in the empirical model is associated with smaller estimates compared to models that do not control for output. This may be because firm optimisation implied by the theoretical model does not hold every period. Stated differently, firm/industry employment may be responding not only to capital and labour costs but also to demand shocks, the exclusion of which may be a source of omitted variable bias. 
2. Technological innovation measured by intellectual property assets (IPAs) is associated with smaller estimates compared to all other measures of innovation. This finding can bridge the evidence gap for two reasons. First, it may indicate that the IPA counts may not reflect the true quality of the technological innovation they protect. Secondly, it addresses the lack of a quantitative measure for how patents and trademarks affect the demand for labour compared to other measures of technological innovation.

3. The effect on manufacturing employment is larger compared to non-manufacturing employment. This is despite the fact that the unit of analysis (firm versus industry) is distributed evenly between manufacturing and non-manufacturing sectors. This finding points out to policy dilemmas in that manufacturing firms/industries that innovate register higher demand for labour compared to services even though the share of manufacturing in total employment is declining in OECD and non-EOCD countries.

4. There is evidence that the effect is larger in OECD compared to non-OECD countries and in the USA compared to all other countries. However, other country data is not associated with significantly different employment-effect estimates. This pattern does not conform to theoretical predictions that different levels of labourmarket flexibility and product-market competition may be associated with different innovation effects on employment. Below, we probe this issue further by estimating separate bivariate meta-regressions for individual countries.

5. Data based on firms/industries classified as highly innovative by primary-study authors is associated with smaller effect-size estimates. This is in contrast to frequent policy statements that establish short-cuts in the relationship between innovation and employment generation. We suggest that future research should investigate non-linearities in the innovation-employment relationship in the light of two empirical patterns from Schumpeterian models. The first concerns the invertedU relationship between innovation intensity and firm survival (Ugur et al., 2016). The relatively lower levels of employment associated with high-innovationintensity may be due to a common pattern among exiting firms with high innovation intensity: a significant drop in the level of employment during the 2-3 year period 
before exit. The second concerns the inverted-U relationship between innovation intensity at the industry level (creative destruction) and total factor productivity (TFP) at the firm level (Aghion et al., 2014). The relative fall in firm's TFP growth rates when industry innovation intensity (creative destruction) increases may be inducing relatively lower levels of demand for labour at the firm or industry levels.

6. Effect-size estimates based on differenced data or fixed-effect estimators are smaller than those based on level data. This is in line with econometric theory, which clearly indicates that differenced or demeaned data is associated with attenuation bias. It also bridges the gap in evidence synthesis for this research field, as narrative reviews are silent on the trade-off between the need to correct for correlated fixed effects (which differencing and fixed-effect estimations do) and the attenuation bias in the latter when the variables are likely to be mis-measured.

Results in Table 3 also allow for some conclusions based on moderately-consistent evidence. Two of these are worth highlighting here. First, and in contrast to the conclusion in Vivarelli (2014), panel data is associated with relatively smaller effect-size estimates compared to crosssection data. This is to be expected econometrically because cross-section data does not allow for taking account of endogeneity and correlated fixed effects. Secondly, and in contrast to the suggestion in Chennells and van Reenen (2002), we find that industry/sector level data is associated with larger estimates compared to firm-level data. These findings suggests that the informational content of the existing estimates may be hampered by data quality, for which econometrics can provide only partial solutions. ${ }^{12}$

In what follows, we will provide further bivariate meta-regression estimates based on isolated evidence pools with a view to examine heterogeneity between countries and between different estimation methods. We undertake this exercise because country dummies and OLS/instrumental variable dummies have turned out to be insignificant in explaining heterogeneity in the overall evidence base. To save space, we present only the PEESE results that take account of the quadratic relationship between primary-study estimates and their standard errors. ${ }^{13}$ In panel A of Table 4, we present the findings for some OECD countries; whereas in Panel B we present the findings for different estimation methods. 
Results in Panel A indicate that the effect of technological innovation on employment do not vary in a monotonic fashion as the level of employment protection legislation (EPL) and product-market regulation (PMR) changes in six OECD countries for which more than 10 observations exist. The countries in Panel A are listed in decreasing order of EPL and PMR indices for the period 1998-2003 (OECD, 2004: 117; OECD, 2013: 29). ${ }^{14}$ In contrast to theoretical predictions, the country-specific effect of technological innovation on labour demand is relatively higher at both ends of the labour- and product-market rigidity indices. The effect is relatively larger in France and Sweden and in the US at the higher and lower ends respectively, compared to Germany, Italy and the UK in the middle.

Our interpretation of this U-shaped pattern is that labour-market flexibility (one of the necessary conditions for job creation under technological innovation) may be high in countries with high and low EPL and PMR. In low EPL and PMR countries such as the US, labourmarket flexibility follows from relatively easier hiring and firing aided by product-market competition. In the high EPL and PMR countries, on the other hand, labour-market flexibility may result from labour unions' agreements to wage flexibility in exchange for job security. This interpretation is in line with non-linear relationships reported by Calmfors and Driffill (1988) and Amable and Gatti (2004).

On the other hand, the results in Panel B confirms the expected upward bias in OLS estimations, which do not take account of endogeneity and correlated fixed effects. The difference between different instrumental variable estimators (GMM difference and system, GMM and 2 SLS/3SLS) is quite small. 
Table 4: Indicators of heterogeneity through bivariate meta-regression estimates

Panel A: Heterogeneity by country (PEESE)

\begin{tabular}{|c|c|c|c|c|c|c|}
\hline & $(1 b)$ & (2b) & $(3 \mathrm{~b})$ & (4b) & (5b) & (6b) \\
\hline VARIABLES & France & Sweden & Germany & Italy & UK & US \\
\hline \multirow[t]{2}{*}{$\beta$} & $0.070 * * *$ & $0.038 * *$ & $0.029 * * *$ & $0.033 * * *$ & $0.029 * * *$ & $0.057 * * *$ \\
\hline & $(0.019)$ & $(0.014)$ & $(0.007)$ & $(0.008)$ & $(0.004)$ & $(0.017)$ \\
\hline \multirow[t]{2}{*}{ Std. error } & -208.155 & -154.473 & -8.166 & -16.023 & 5.781 & $-25.853 * * *$ \\
\hline & $(167.880)$ & $(157.674)$ & $(12.339)$ & $(20.498)$ & $(9.020)$ & $(8.644)$ \\
\hline Observations & 11 & 23 & 95 & 11 & 171 & 95 \\
\hline Number of groups & 2 & 2 & 8 & 3 & 4 & 5 \\
\hline LR Test chi ${ }^{2}$ & 41.263 & 6.648 & 15.921 & 22.966 & 44.333 & 20.529 \\
\hline $\mathrm{P}>\mathrm{chi}^{2}$ & 0.000 & 0.036 & 0.000 & 0.000 & 0.000 & 0.000 \\
\hline Log-likelihood (HM) & -26.321 & -65.781 & -182.228 & -20.337 & -310.868 & -241.610 \\
\hline Log-likelihood $(\mathrm{CM})^{\#}$ & -26.321 & -66.013 & -192.098 & -20.337 & -312.035 & -250.223 \\
\hline $\begin{array}{l}\text { EPL / PMR (Highest to } \\
\text { lowest) }\end{array}$ & 1 & 2 & 3 & 4 & 5 & 6 \\
\hline
\end{tabular}

Panel B: Heterogeneity by estimator (PEESE)

\begin{tabular}{lcccc}
\hline & $(1 \mathrm{~b})$ & $(2 \mathrm{~b})$ & $(3 \mathrm{~b})$ & $(4 \mathrm{~b})$ \\
Dependent variable: $t-v a l u e$ & OLS & GMM-All & GMM-Sys & 2SLS - 3SLS \\
\hline & & & & \\
$\beta$ & $0.035^{* * *}$ & $0.015^{* * *}$ & $0.014 * * *$ & $0.012 * * *$ \\
Std. error & $(0.004)$ & $(0.004)$ & $(0.005)$ & $(0.004)$ \\
& $-6.764 *$ & $51.931 * *$ & $67.531 * *$ & $56.347 * * *$ \\
\hline Observations & $(3.804)$ & $(20.360)$ & $(27.545)$ & $(19.647)$ \\
Studies & 297 & 111 & 64 & 120 \\
LR Test chi & 21 & 8 & 6 & 11 \\
P> chi & 25.515 & 39.975 & 31.927 & 42.382 \\
Log-likelihood (HM) & 0.000 & 0.000 & 0.000 & 0.000 \\
Log-likelihood (Comp. model) & -681.760 & -208.530 & -129.786 & -227.030
\end{tabular}

Standard errors in parentheses. $* * * \mathrm{p}<0.01, * * \mathrm{p}<0.05, * \mathrm{p}<0.1$. All are estimated as two-level hierarchical models with random intercepts. \#: HM is hierarchical model; CM is comparator model. \#\#: EPL is employment protection legislation; PMR is product-market regulations. Both indicate rigidities in the labour and product markets, respectively. 


\section{Conclusions}

The analysis above demonstrates that meta-analysis is an effective method of synthesizing the evidence on the relationship between technological innovation and employment estimated through some variant of the DLDM. The method has enabled us to verify the qualitative conclusions put forward in existing reviews and to shed new light on the effects of moderating factors with respect to which they are either silent or inconclusive. We provide partial empirical support to two conclusions reported in prior reviews: (i) technological innovation increases the demand for skilled labour more than unskilled labour; and (ii) primary studies published after 2000 tend to report relatively larger 'effect-size' estimates. However, the empirical support for these conclusions is qualified: the effect on skilled-labour demand is not larger (in fact it is smaller) than the effect on mixed-skills labour demand; and that the increased availability of panel data after 2000 is not necessarily the driver of larger estimates reported in more recent studies. If anything, estimates based on panel-data are relatively smaller than those based on cross-section or time-series data.

We have demonstrated that best practice in meta-regression analysis can be enhanced through explicit modeling of between- and within-study dependence. Hierarchical models are wellsuited for this purpose for two reasons. First, they are flexible enough to allow for correct choice between nested models and estimators on the basis of LR tests. Secondly, they allow for consistent 'effect-size' estimates and correct inference at a relatively small cost that may arise when the normality assumption about the error term is violated.

Our findings suggest that narrative review conclusions may be incorrect when they draw on highly selected estimates. This was evident with respect to the effects of process and product innovation on mixed-skills labour demand. The selection bias in these evidence pools is in the direction of theoretical predictions; and the level of selection is so high that the effect-size estimates turn out to be the opposite of what the narrative reviews report. Our findings are also in contradiction with narrative review conclusions concerning the employment effects at the industry level (which turns out to be relatively larger than firm-level effect) and within highinnovation-intensity firms or industries (which turns out to be smaller than the excluded categories). 
They also shed new light on some moderating factors with respect to which the narrative reviews are either silent or inconclusive. Specifically, we found that: (i) the inclusion of output in the DLDM is associated with smaller innovation effects on employment; (ii) measuring technological innovation with $R \& D$ investment has no systematic effect on reported estimates, but the reported estimates are relatively smaller when innovation is measured with patents or trademarks and relatively larger when innovation is measured with investment in ICT; (iii) the effect of labour- and product-market regulation on the relationship between innovation and employment is more nuanced than the narrative review conclusions in that both high and low regulation countries may derive larger employment gains from innovation as labour unions trade off job security with wage flexibility in high-regulation countries.

This review suggests that persistent heterogeneity and lack of conformity between metaanalysis findings and some theoretical predictions (particularly those related to process and product innovation) raises important questions about the informational content of the existing evidence. The latter may be constrained by data quality and modeling issues. Chennells and van Reenen (2002) provide an authoritative account of the difficulties involved in measuring innovation as a proxy for the unobservable technological change. Therefore, we suggest that investment in better-quality data is necessary to reduce the risk of mismeasurement. In our view, the transition to capitalisation of $\mathrm{R} \& \mathrm{D}$ expenditures is a step in the right direction because it will bring a common approach to $R \& D$ deflators and to the building of $R \& D$ capital stock from $R \& D$ investments. We also think that the R\&D capital should be augmented with other intangible assets to create a measure of knowledge capital as suggested by Clayton et al. (2009).

Irrespective of the innovation measure adopted, knowledge diffusion remains a central issue for modeling. In the literature on R\&D and productivity (e.g., Griliches, 1979; Hall et al., 2010; Hall, 2011) knowledge diffusion is modelled as a separate source of productivity because it is considered as complement rather than substitute to own knowledge capital. In the innovation and employment literature reviewed here none of the studies control for knowledge diffusion as a separate source of technological change. Although constructing the external knowledge pools poses additional measurement issues (Griliches, 1992), its exclusion from the theoretical and empirical models is rather ad hoc - and may be a source of omitted variable bias.

Another modeling issue is the lag structure in the relationship between the knowledge stock (both own and external knowledge stock) and employment. Fifty percent of the included 
studies use contemporaneous values of employment and innovation and $31 \%$ use between 1 and 3 lags for technological innovation, with the remaining 19\% using more than 3 lags. The variation in the lag choices appears to be driven by empirical concerns rather than justifications on theoretical grounds. Therefore, we suggest better linkage with the literature on innovation and growth/productivity with a view to highlight not only the need for taking account of the lag structure in the relationship between technological innovation and employment, but also to acknowledge the difficulties in identifying the lag structure in firm-level as opposed to industry-level data.

A final modeling issue concerns the need for explicit incorporation of market power and creative destruction into the theoretical and empirical models. The Schumpeterian growth literature (Aghion et al., 2014) provides useful insights about the rationale for their inclusion in the growth models and their implications for growth. One way in which the Schumpeterian insights can be incorporated into the derived labour demand model is to allow for interactions between technological innovation and market power. Another way is to treat innovation intensity in the industry or the region not only as a source of knowledge spillovers but also as a source of creative destruction that makes the firm's or the industry's own technology obsolete. 


\section{References}

\section{General references}

Aghion, P., U. Akcigit, and P. Howitt (2014). What do we learn from Schumpeterian growth theory? In P. Aghion and S. Durlauf (eds), Handbook of Economic Growth, Vol. 2. Amsterdam: Elsevier, pp. 515-563.

Amable, B. and D. Gatti (2004). Product market competition, job security, and aggregate employment. Oxford Economic Papers, 56(4), 667-686.

Antonioli, D., R. Manzalini and P. Pini (2011). Innovation, workers skills and industrial relations: Empirical evidence from firm-level Italian data. Journal of Socio-Economics, 40(3), 312-326.

Benavente, J. M. and R. Lauterbach (2008). Technological innovation and employment: Complements or substitutes? European Journal of Development Research, 20(2), 318-329.

Berman, E., J. Bound and Z. Griliches (1994). Changes in the demand for skilled labor within U.S. manufacturing: evidence from the annual survey of manufactures. Quarterly Journal of Economics 109(2), 367-397.

Berman, E., J. Bound and S. Machin (1998). Implications of skill-biased technological change: International evidence. Quarterly Journal of Economics, 113(4), 1245-1279.

Berman, E., Somanathan, R., and Tan, H. W. (2005). Is skill-biased technological change here yet?: Evidence from indian manufacturing in the 1990's. World Bank Policy Research Working Papers, Washington DC.

Blechinger, D., Kleinknecht, A., Licht, G., and Pfeiffer, F. (1998). The impact of innovation on employment in Europe: an analysis using CIS data. ZEW-Dokumentation.

Blechinger, D., and Pfeiffer, F. (1999). Skill structure, employment and technological progress. Jahrbücher für Nationalökonomie und Statistik, 218(1-2), 128-128.

Bogliacino, F. and M. Pianta (2010). Innovation and employment. A reinvestigation using revised Pavitt classes. Research Policy, 39(6), 799-809.

Calmfors, L. and J. Driffill (1988). Bargaining structure, corporatism and macroeconomic performance, Economic Policy, 3(6), 14-61.

Card, D. and A. B. Krueger (1995). Time-series minimum-wage studies: a meta-analysis. American Economic Review, 85(2), 238-243.

Chennells, L. and J. van Reenen (2002). Technical change and the structure of employment and wages: A survey of the microeconometric evidence. In N. Greenan, Y. L'Horty and J. Mairesse (eds), Productivity, Inequality and the Digital Economy, Cambridge, MA: MIT Press, pp.175-223.

Ciriaci, D., P. Moncada-Paternò-Castello and P. Voigt (2016). Innovation and job creation: A sustainable relation? Eurasian Business Review, 6(2), 189-213.

Clayton, T., M. Dal Borgo and J. Haskel (2009). An innovation index based on knowledge capital investment: Definition and results for the UK market sector. IZA Discussion Papers, no. 4021.

Cohen, J. (1988). Statistical Power Analysis for the Behavioural Sciences. Hillsdale, NJ: Erlbaum.

Demidenko, E. (2004). Mixed Models: Theory and Applications. Hoboken, NJ: Wiley.

Dickersin, K., and Y. I. Min (1993). Publication bias: the problem that won't go away. Annals of the New York Academy of Sciences, 703(1), 135-148. 
Doucouliagos, H. (2011). How large is large? Preliminary and relative guidelines for interpreting partial correlations in economics. Deakin Faculty of Business and Law, $\begin{array}{llll}\text { Working Papers, } & \text { no. } & \text { SWP } & \end{array}$ https://www.deakin.edu.au/_data/assets/pdf_file/0003/408576/2011_5.pdf

Doucouliagos, H., and P. Laroche (2009). Unions and profits: A meta-regression analysis. Industrial Relations: A Journal of Economy and Society, 48(1), 146-184.

Doucouliagos, H., and Stanley, T. (2009). Publication selection bias in minimum-wage research? A metaregression analysis. British Journal of Industrial Relations, 47(2), 406428.

Draca, M., R. Sadun and J. Van Reenen (2007). Productivity and ICT: A review of the evidence. In R. Mansell (Ed.), The Oxford Handbook of Information and Communication Technologies. Oxford University Press, Oxford and New York, pp. 100-147.

Egger, M., G. D Smith, M. Schneider, and C. Minder (1997). Bias in meta-analysis detected by a simple, graphical test. British Medical Journal, 316, 629-34.

Griliches, Z. (1979). Issues in assessing the contribution of research and development to productivity growth. Bell Journal of Economics, 10(1), 92-116.

Griliches, Z. (1992). The Search for R\&D Spillovers. The Scandinavian Journal of Economics, 94(Supplement), 29-47.

Griliches, Z. and J. Mairesse (1995). Production functions: The search for identification. NBER Working Papers No. 5067. National Bureau of Economic Research.

Hall, B. H. (2011). Innovation and productivity. NBER Working Papers, No. 17178. National Bureau of Economic Research.

Hall, B. H., Lotti, F., and Mairesse, J. (2008). Employment, innovation, and productivity: evidence from Italian microdata. Industrial and Corporate Change, 17(4), 813-839.

Hall, B. H., J. Mairesse and P. Mohnen (2010). Measuring the returns to R\&D. In B. H. Hall and N. Rosenberg (eds.), Handbook of the Economics of Innovation, vol. 2, Elsevier, New York.

Harbord, R. M and J. P. Higgins (2008). Meta-regression in Stata. Stata Journal, 8(4), 493519.

Harrison, R., Jaumandreu, J., Mairesse, J., and Peters, B. (2008). Does innovation stimulate employment? A firm-level analysis using comparable micro-data from four European countries. NBER Working Paper No. 14216.

Harrison, R., Jaumandreu, J., Mairesse, J., Peters, B., 2014. Does innovation stimulate employment? A firm-level analysis using comparable micro-data from four European countries. International Journal of Industrial Organization, 35(July), 29-43.

Higgins, J. P., S. G. Thompson, J. J. Deeks and D. G. Altman (2003). Measuring inconsistency in meta-analyses. British Medical Journal, 327(7414), 557-560.

Ioannidis, J. P. (2005). Contradicted and initially stronger effects in highly cited clinical research. Jama, 294(2), 218-228.

Katsoulacos, Y. S. (1986). The employment effect of technical change: a theoretical study of new technology and the labour market. University of Nebraska: Wheatsheaf

Machin, S. (2001). The changing nature of labour demand in the new economy and skill-biased technology change. Oxford Bulletin of Economics and Statistics, 63 (s1), 753-776.

McCulloch, C. E., S. R. Searle, and J. M. Neuhaus (2008). Generalized, Linear, and Mixed Models (2nd ed). Hoboken, NJ: Wiley.

Mitra, A. and A. Jha (2015). Innovation and employment: A firm level study of Indian industries. Eurasian Business Review, 5(1), 45-71.

Mokyr, J., C. Vickers and N. L. Ziebarth (2015). The history of technological anxiety and the future of economic growth: Is this time different? Journal of Economic Perspectives, 29(3), $31-50$. 
OECD (2004). Employment Outlook 2004. ISBN 92-64-10812-2. https://www.oecd.org/employment/emp/34846856.pdf

Pianta, M. (2004). Innovation and employment. In Jan Fagerberg, David C. Mowery, and Richard R. Nelson (eds), The Oxford Handbook of Innovation, Oxford: Oxford University Press, 568-598.

Piva, M. (2003). The impact of technology transfer on employment and income distribution in developing countries: A survey of theoretical models and empirical studies. ILO Policy Integration Department Working Papers, no. 15. http://www.ilo.org/public/libdoc/ilo/2004/104B09_36_engl.pdf

Piva, M., and M. Vivarelli (2005). Innovation and employment: Evidence from Italian microdata. Journal of Economics, 86(1), 65-83.

Simmons, J. P., L. D. Nelson and U. Simonsohn (2011). False-positive psychology undisclosed flexibility in data collection and analysis allows presenting anything as significant. Psychological science, 22(11), 1359-1366.

Snijders. T. and R. Bosker (2012). Multilevel Analysis: An Introduction to Basic and Advanced Multilevel Analysis (2nd ed.), London: Sage.

Spiezia, V., M. Vivarelli and M. Piva (2002). Technological change and employment: a twofold theoretical critique and the empirical evidence. Economia e Politica Industriale. Fascicolo 115, 1000-1032.

Stanley, T. D. (2005). Beyond publication bias. Journal of Economic Surveys, 19(3), 309-45.

Stanley, T. (2008). Meta-regression methods for detecting and estimating empirical effects in the presence of publication selection. Oxford Bulletin of Economics and Statistics, 70(2), 103-127.

Stanley, T., and Doucouliagos, H. (2007) Identifying and correcting publication selection bias in the efficiency-wage literature: Heckman meta-regression. Deakin University Economics Working Paper Series 2007, 11.

Stanley, T. D., and Doucouliagos, H. (2014). Meta-regression approximations to reduce publication selection bias. Research Synthesis Methods, 5(1), 60-78.

Stanley, T. D., Doucouliagos, H., Giles, M., Heckemeyer, J. H., Johnston, R. J., Laroche, P., . . . Rost, K. (2013). Meta-Analysis of Economics Research Reporting Guidelines. Journal of Economic Surveys, 27(2), 390-394.

Sterne, J.A. and R.M. Harbord (2004). Funnel plots in meta-analysis. The Stata Journal, 4(2), $127-141$.

Ugur, M., E.Trushin and E. Solomon. (2016). Inverted-U relationship between R\&D intensity and survival: Evidence on scale and complementarity effects in UK data. Research Policy, 45(7), 1474-1492.

Vivarelli, M. (2014). Innovation, employment and skills in advanced and developing countries: a survey of economic literature. Journal of Economic Issues, 48(1), 123-154.

Xu B. and W. Li (2008). Trade, technology, and China's rising skill demand. Economics of Transition, 16(1), 59-84.

\section{Primary studies included in the meta-analysis}

Akcigit, U., and Kerr, W. R. (2012). Growth through heterogeneous innovations. Penn Institute for Economic Research (PIER) Working Paper No. 10-035.

Araújo, B. C., Bogliacino, F., and Vivarelli, M. (2011). Technology, trade and skills in Brazil: evidence from micro data. CEPAL Review(105).

Berndt, E. R., Morrison, C. J., and Rosenblum, L. S. (1992). High-tech capital formation and labor composition in US manufacturing industries: an exploratory analysis 
Blanchflower, D. G., and Burgess, S. M. (1995). New technology and jobs: Comparative evidence from a two country study. Paper written for the Conference on Technology, Firm Performance and Employment at the National Academy of Sciences, Washington DC, May 1995. http://www.dartmouth.edu/ blnchflr/papers/newtech.pdf

Blechinger, D., Kleinknecht, A., Licht, G., and Pfeiffer, F. (1998). The impact of innovation on employment in Europe: an analysis using CIS data: ZEW-Dokumentation, no. 98-02. ftp://ftp.zew.de/pub/zew-docs/docus/dokumentation9802.pdf

Bogliacino, F., Piva, M., and Vivarelli, M. (2012). R\&D and employment: An application of the LSDVC estimator using European microdata. Economics Letters, 116(1), 56-59.

Bogliacino, F., and Vivarelli, M. (2012). The job creation effect of R\&D expenditures. Australian Economic Papers, 51(2), 96-113.

Brouwer, E., Kleinknecht, A., and Reijnen Jeroen, O. N. (1993). Employment growth and the innovation at the firm level: An empirical study. Journal of Evolutionary Economics, 3(2), 153.

Buerger, M., Broekel, T., and Coad, A. (2012). Regional dynamics of innovation: Investigating the co-evolution of patents, research and development (R\&D), and employment. Regional Studies, 46(5), 565-582.

Carlsson, M., and Smedsaas, J. (2007). Technology Shocks and the Labor-Input Response: Evidence from Firm-Level Data. Journal of Money, Credit and Banking, 39(6), 1509-1520.

Coad, A., and Rao, R. (2010). Firm growth and R\&D expenditure. Economics of Innovation and New Technology, 19(2), 127-145.

Coad, A., and Rao, R. (2011). The firm-level employment effects of innovations in high-tech US manufacturing industries. Journal of Evolutionary Economics, 21(2), 255-255.

Conte, A., and Vivarelli, M. (2011). Imported Skill-Biased Technological Change in Developing Countries. Developing Economies, 49(1), 36-65.

Cozzarin, B. P. (2004). Innovation quality and manufacturing firms' performance in Canada. Economics of Innovation and New Technology, 13(3), 199-216.

Evangelista, R., and Vezzani, A. (2011). The impact of technological and organizational innovations on employment in European firms. Industrial and Corporate Change, 21(4), 871-899.

Giuliodori, D., and Stucchi, R. (2010). Innovation and job creation in a dual labor market: evidence from Spain. MPRA Paper No. 31297.

Greenan N. and D. Guellec (2000). Technological innovation and employment reallocation. Labour. 14(4): 547-590.

Greenhalgh, C., Longland, M., and Bosworth, D. (2001). Technological activity and employment in a panel of UK firms. Scottish Journal of Political Economy, 48(3), 260-282.

Greenhalgh, C., Rogers, M., and Schautschick, P. (2011). Do firms that create intellectual property also create and sustain more good jobs? Evidence for UK firms, 2000-2006. Princeton University, Industrial Relations Working Papers: 1319.

Lachenmaier, S., and Rottmann, H. (2007). Employment effects of innovation at the firm level. Jahrbücher für Nationalökonomie und Statistik, 227(3), 254-254.

Lachenmaier, S., and Rottmann, H. (2011). Effects of innovation on employment: a dynamic panel analysis. International Journal of Industrial Organization, 29(2), 210-210.

Lucchese, M., and Pianta, M. (2012). Innovation and employment in economic cycles. Comparative Economic Studies, 54(2), 341-359.

Mastrostefano, V., and Pianta, M. (2009). Technology and jobs. Economics of Innovation and New Technology, 18(8), 729-741.

Osterman, P. (1986). The impact of computers on the employment of clerks and managers. Industrial and Labor Relations Review, 39(2), 175-186. 
Pianta, M. (2000). The employment impact of product and process innovations. In M. Pianta, and Vivarelli, M. (Ed.), The employment impact of innovation: Evidence and policy (pp. 7795): Routledge.

Piva, M., and Vivarelli, M. (2004a). The determinants of the skill bias in Italy: R\&D, organisation or globalisation? Economics of Innovation and New Technology, 13(4), 329347.

Piva, M., and Vivarelli, M. (2004b). Technological change and employment: some micro evidence from Italy. Applied Economics Letters, 11(6), 373-376.

Rottmann, H., and Ruschinski, M. (1998). The Labour Demand and the Innovation Behaviour of Firms: An Empirical Investigation for West German Manufacturing Firms Journal of Economics and Statistics, 217(6), 741-752.

Smolny, W. (1998). Innovations, prices and employment - A theoretical model and an empirical application for West German manufacturing firms. Journal of Industrial Economics, 46(3), 359-381.

Smolny W (2002) Employment adjustment at the firm level: A theoretical model and an empirical investigation for West German manufacturing firms. Labour. 16(1): 65-68.

Srour, I., Taymaz, E., and Vivarelli, M. (2013). Skill-biased technological change and skillenhancing trade in Turkey: evidence from longitudinal microdata.

van Reenen, J. (1997). Employment and technological innovation: Evidence from UK Manufacturing firms. Journal of Labor Economics, 15(2), 255-284.

Westermanna, G., and Schaeferb, H. (2001). Localised Technological Progress And IntraSectoral Structures Of Employment: A Data Envelopment Analysis. Economics of Innovation and New Technology, 10(1), 23-44.

Yang, C. H., and Lin, C. H. A. (2008). Developing employment effects of innovations: Microeconometric evidence from Taiwan Developing Economies 46(2), 109-134.

Yochum, G., and Rhiel, G. S. (1990). Employment and Changing Technology in the Postwar Railroad Industry. Industrial Relations, 29(3), 479-490. 


\section{Appendix}

\section{Part 1: Derived labour demand model (DLDM) and competing models}

This study meta-analyses 'effect-size' estimates from a DLDM, which is based on an industrylevel production function (A1) with constant elasticity of substitution between capital and labour (van Reenen, 1997; Chennells and van Reenen, 2002).

$Q=T\left[(A L)^{(\sigma-1) / \sigma}+(B K)^{(\sigma-1) / \sigma}\right]^{\sigma /(1-\sigma)}$

In (A1), $Y$ is output, $L$ is employment, and $K$ is capital stock. Of the technology parameters, $T$, $A$ and $B$ represent Hicks-neutral, Harrod-neutral and Solow-neutral technological change, respectively. ${ }^{15}$ Finally, $\sigma$ is the non-unitary constant elasticity of substitution between capital and labour.

Assuming profit maximisation, the level of employment that satisfies the first-order condition for profit-maximisation is:

$\log L=\log Q-\sigma \log (W / P)+(\sigma-1) \log A$

Allowing capital to vary too, we can substitute for output $(Q)$ in (A3) using the capital stock $(\mathrm{K})$ and the cost of capital (R). Then the DLDM can be written as follows:

$\log L=(\sigma-1) \log (A / B)-\sigma \log (W / P)+\log K+\sigma \log R$

Finally, replacing the unobserved technology variables $(A$ and $B)$ with an appropriate measure of innovation, and assuming that the cost of capital is constant across industries but varies over time, the stochastic version of the DLDM can be written as:

$\log L_{i t}=\gamma \log (\text { Tech_Innov })_{i t}+\beta_{1} \log (W / P)_{i t}+\beta_{2} \log K_{i t}+\tau_{t}+\varepsilon_{i t}$

The skill share model (Berman et al., 1994; 1998 and Machin, 2001) differs from the DLDM in two ways: (i) it begins with a translog cost function as the dual of the production function; and (ii) it relaxes the assumption of Hicks-neutral technology by assuming that the marginal rate of substitution between inputs (e.g., capital and labour) is not constant across skill types.

Given a translog cost function, the share of labour in total cost can be written as:

$S_{i}=P_{i} X_{i} / T C=\frac{d \ln T C}{d \ln P_{i}}=\alpha_{i}+\sum_{j} \gamma_{i j} \ln P_{j}+\gamma_{i y} \ln Y+\gamma_{i t} t$

Where $i$ and $j$ are unskilled and skilled labour inputs, $P$ is price (wage) of unskilled and skilled labour, $Y$ is output and $t$ is time (representing technological change). 
Replacing the time-oriented technology measure with observable proxy for technology $(T)$ and assuming that capital is a quasi-fixed input, we can rewrite:

$S_{i}=\alpha_{i}+\sum_{j} \gamma_{i j} \ln P_{j}+\gamma_{i y} \ln Y+\gamma_{i k} \ln K+\gamma_{i z} T$

Given two types of labour ( $u$ for unskilled and s for skilled labour), we can express the relative demand between unskilled labour (u) and skilled labour (s) as the difference in cost shares:

$\left(S_{i t}-S_{j t}\right)=\left(\alpha_{i}-\alpha_{j}\right)+\sum_{j}\left(\gamma_{p i}-\gamma_{p j}\right) \ln P_{j t}+\left(\gamma_{y i}-\gamma_{y j}\right) \ln Y_{t}+\left(\gamma_{k i}-\gamma_{k j}\right) \ln K_{t}+\left(\gamma_{T i}-\right.$ $\left.\gamma_{T j}\right) T_{t}$

Imposing constant returns to scale and homogeneity of degree one in prices, the reduced form is:

$\Delta S_{j}^{*}=\beta_{0}+\beta_{1} \Delta \ln \left(P_{j} / P_{i}\right)+\beta_{2} \Delta \ln (K / Y)+\beta_{3} \Delta Z$

Here $\Delta S_{s}^{*}$ is the first-difference of skilled labour share in wage bill. Capital investment data is used instead of capital stock data - unlike the derived labour demand model where capital stock is required.

Skill-share models are not included in this meta-analysis because the outcome (dependent) variable measures the share of skilled (or unskilled) labour in total employment (or wage bill) - rather than the aggregate demand for skilled or unskilled labour perse.

Finally, in the innovation decomposition model (Hall et al., 2008; Harrison et al., 2008 and 2014), a firm can produce two types of products: old or only marginally modified products $(j=1)$ and new or significantly improved products $(j=2)$. The firm is observed in two different periods, $t=1$ and $t=2$. Outputs of old and new products in year $t$ are denoted by $Y_{1 t}$ and $Y_{2 t}$, respectively. In year $t=1$, all products are old products by definition, so $Y_{12}$ is zero. In period $t=2$, the firm may produce old and new products, represented by $Y_{21}$ and $Y_{22}$. Given this setup, the production function is stated as follows:

$Y_{j t}=T * F\left(K_{j t}+L_{j t}+M_{j t}\right) e^{\left(\eta+\pi_{j t}\right)}$

Here, $T$ is Hicks-neutral technology; $K$ is capital, $L$ is labour and $M$ is materials. The firmspecific fixed effect $(\eta)$ represents all unobservable factors that make a firm more (or less) productive compared to the average firm using the same technology. Finally, $\pi$ represents all unobservable shifts in the production function for reasons other than technological change, with an expected value of $E\left(\pi_{i t}\right)=0$. 
Given technology $(T)$, the cost function can be written as follows:

$C\left(W_{i t}, Y_{i t}, T_{i t}\right)=\frac{C\left(W_{i t}\right)}{\left.T_{i t} e^{(\eta+\pi} j t\right)} Y_{i t}+F C_{i}$

Where, $\frac{C\left(W_{i t}\right)}{\left.T_{i t} e^{(\eta+\pi} j t\right)}$ is marginal cost and $F C_{i}$ is fixed cost.

Employment growth in this model can be decomposed as follows:

$\frac{\Delta L}{L}=-\left(\ln T_{12}-\ln T_{11}\right)+\left(\ln Y_{12}-\ln Y_{11}\right)+\frac{T_{11}}{T_{22}} \frac{Y_{22}}{Y_{11}}-\left(\pi_{12}-\pi_{11}\right)$

Using small case letter to represent growth, the model can be re-written as follows:

$l=\alpha_{0}+\alpha_{1} d+y_{1}+\beta_{2} y_{2}+u$

Here $y_{1}$ and $y_{2}$ are rates of growth in output due to change in the production of old and new products, respectively. Parameter $\alpha_{0}$ is expected to have a negative sign and represents the average efficiency growth in the production of the old product. Parameter $\alpha_{1}$ measures the effect of process innovation on employment when process innovation is captured through a binary variable $d$. The effect of output growth due to production of old products is captured by the unitary coefficient on $\boldsymbol{y}_{\boldsymbol{1}}$. Finally, the effect of product innovation on employment is captured by $\beta_{2}$.

In practice, however, real firm output is not observed as product price deflators are available only at the industry level. Denoting nominal output growth by $g$ and industry-level prices with $p$; and pulling the growth in old products to the left, we obtain the model to be estimated as follows:

$l-\left(g_{1}-p\right)=\alpha_{0}+\alpha_{1} d+\beta_{2} g_{2}+v$

The difference with the DLDM is the omission of wages, which disappear when the labour demand due to production of old and new products is decomposed. Furthermore, the measures of technological innovation are either a binary variable for process innovation or product innovations count for product innovation.

\section{Part 2: Hierarchical models to be estimated}

The random-intercept (RI) and random-intercept-and-slopes (RIS) hierarchical PET-FAT models are specified as follows: 


$$
\begin{aligned}
& t_{i j k}=\alpha^{h 1}+\beta^{h 1}\left(1 / p c c_{-} s e_{i j k}\right)+v_{0 j}^{h 1}+v_{0 k}^{h 1}+\varepsilon_{i j k} \\
& t_{i j k}=\alpha^{h 2}+\beta^{h 2}\left(1 / s e_{-} p c c_{i j k}\right)+v_{0 j}^{h 2}+v_{0 k}^{h 2}+v_{1 k}^{h 2}\left(1 / s e_{-} p c c_{i j k}\right)+\epsilon_{i j k}
\end{aligned}
$$

Here, subscripts $i$ and $j$ and $k$ refer to individual estimates (PCC), analytic clusters, and primary studies, respectively; and $\varepsilon_{i j k}$ and $\epsilon_{i j k}$ are error terms divided by the standard errors. Regression coefficients $\alpha^{h}$. and $\beta^{h}$. measure selection bias and genuine effect, respectively. They are estimated with maximum likelihood (ML). Of the random-effect components, $v_{0 j}^{h}$ is estimated as the variance of the random effects at the study level; $v_{0 k}^{h}$ is the random effects at the level of analytic cluster (pairs of innovation and skill types); and $v_{1 k}^{h}$ is estimated as the variance of random slopes (within-study variation). The choice between RI and RIS models in (A14) and (A15) will be guided by LR tests.

The RI and RIS hierarchical PEESE models are given below:

$$
\begin{aligned}
& t_{i j k}=\alpha^{h 3} s e_{-} p c c_{i j k}+\beta^{h 3}\left(1 / s_{-} p c c_{i j k}\right)+v_{0 j}^{h 3}+v_{0 k}^{h 3}+\lambda_{i j k} \\
& t_{i j k}=\alpha^{h 4} s e_{-} p c c_{i j k}+\beta^{h 4}\left(1 / s e_{-} p c c_{i j} k\right)+v_{0 j}^{h 4}+v_{0 k}^{h 4}+v_{1 k}^{h 4}\left(1 / s e_{-} p c c_{i j k}\right)+w_{i j k}
\end{aligned}
$$

All subscripts, random effects, error terms and parameters are as defined above.

The RI and RIS specifications of the multivariate meta-regression model (MVMRM) are given in $(8 a)$ and $(8 b)$, respectively:

$$
\begin{aligned}
t_{i j k}= & \alpha^{h 5} s e_{p c c_{i j k}}+\beta^{h 5}\left(1 / p c c_{s e_{i j k}}\right)+\sum_{m} \theta_{m} Z_{m}\left(1 / s e_{p c c_{i j k}}\right)+v_{0 j}^{h 5} \\
& +v_{0 k}^{h 5}+\xi_{i j k} \\
t_{i j k}= & \alpha^{h 6} s e_{-} p c c_{i j k}+\beta^{h 6}\left(1 / p c c_{s e_{i j k}}\right)+\sum_{m} \theta_{m} Z_{m}\left(1 / s e_{-} p c c_{i j k}\right)+v_{0 j}^{h 6}+v_{0 k}^{h 6}+ \\
& v_{1 k}^{h 6}\left(1 / p c c_{-} s e_{i j k}\right)+\mu_{i j k}
\end{aligned}
$$

The $m x l$ vector of covariates $\left(Z_{m}\right)$ are the observed sources of variation as defined in Table 2 in main text above. The corresponding summary statistics for these moderating factors are in Table A2 in the Appendix below. 


\section{Part 3: Tables}

Table A1: Technological innovation and employment: Overview of the evidence base

\begin{tabular}{|c|c|c|c|c|c|c|c|c|c|c|c|}
\hline Study & $\begin{array}{l}\text { Publication } \\
\text { type }\end{array}$ & Country & $\begin{array}{l}\text { Unit of analysis } \\
\text { (count) }\end{array}$ & $\begin{array}{l}\text { Data } \\
\text { period }\end{array}$ & Innovation measure & Innovation type & $\begin{array}{l}\text { Skill } \\
\text { type }\end{array}$ & $\begin{array}{l}\text { Estimation } \\
\text { method }\end{array}$ & $\begin{array}{l}\text { Median } \\
\text { PCC }\end{array}$ & $\begin{array}{l}\text { Median } \\
\text { t-value }\end{array}$ & $\begin{array}{l}\text { Reported } \\
\text { estimates }\end{array}$ \\
\hline Akcigit and Kerr (2012) & Working paper & US & Firm (n.a.) & 1978-1992 & IPA & Undifferentiated & Mixed & OLS & 0.060 & 7.250 & 11 \\
\hline Araujo et al (2011) & Working paper & Non OECD & Firm (10810) & $1997-2005$ & ICT, IPA & Undifferentiated & Unskilled & GMM & 0.008 & 2.188 & 4 \\
\hline Berndt et al (1992) & Working paper & US & Industry (20) & 1968-1986 & ICT & Undifferentiated & Mixed & OLS & 0.257 & 0.995 & 60 \\
\hline Blanchflower and Burgess (1995) & Working paper & OECD Mixed & Firm (889) & 1989 & ICT & Undifferentiated & Mixed & OLS & 0.072 & 1.910 & 34 \\
\hline Blechinger et al (1998) & Working paper & Mixed & Firm (16374) & 1992 & $\begin{array}{l}\text { R\&D, Process innovation, } \\
\text { Innovation count }\end{array}$ & Undifferentiated & Mixed & OLS & 0.008 & 0.471 & 21 \\
\hline Bogliacino and Vivarelli (2012) & Journal article & OECD mixed & Sector (25) & $1996-2005$ & $R \& D$ & Undifferentiated & Mixed & GLS & 0.067 & 3.000 & 11 \\
\hline Bogliacino et al (2012) & Journal article & OECD mixed & Firm (677) & $1990-2008$ & $R \& D$ & Undifferentiated & Mixed & LSDVC & 0.042 & 2.300 & 5 \\
\hline Brouwer et al (1993) & Journal article & Netherlands & Firm (771) & 1983-1988 & R\&D, Product innovation & Product & Mixed & OLS & 0.008 & 0.225 & 2 \\
\hline Buerger et al (2012) & Journal article & Germany & Industry (270) & $1999-2005$ & IPA, R\&D & Undifferentiated & Mixed & LAD & 0.022 & 0.540 & 24 \\
\hline Carlsson and Smedsaas (2007) & Journal article & Sweden & Firm (1516) & 1989-1996 & ICT & Undifferentiated & Mixed & FE WG & 0.027 & 2.321 & 8 \\
\hline Coad and Rao (2010) & Journal article & Sweden & Firm (1577) & 1973-2004 & $R \& D$ & Undifferentiated & Mixed & LAD & 0.035 & 3.560 & 15 \\
\hline Coad and Rao (2011) & Journal article & US & Firm (527) & 1963-1998 & $R \& D$ & Undifferentiated & Mixed & LSDVC & 0.086 & 5.560 & 16 \\
\hline Conte and Vivarelli (2011) & Journal article & Non OECD & Industry (28) & 1980-1991 & ICT & Undifferentiated & Unskilled & GMM & 0.034 & 2.004 & 6 \\
\hline Cozzarin (2004) & Journal article & Canada & Firm (5212) & 1999 & $\begin{array}{l}\text { IPA, R\&D, Innovation } \\
\text { count }\end{array}$ & Undifferentiated & Mixed & GLS & 0.009 & 0.678 & 9 \\
\hline Evangelista and Vezzani (2011) & Journal article & OECD mixed & Firm (57856) & 2002-2004 & Process Innovation & Process & Mixed & $3 S L S$ & 0.008 & 1.453 & 3 \\
\hline Giuliodori and Stucchi (2010) & Working paper & Spain & Firm (2350) & $1991-2005$ & $\begin{array}{l}\text { Process and Product } \\
\text { Innovation }\end{array}$ & $\begin{array}{l}\text { Both product and } \\
\text { process }\end{array}$ & Mixed & FE WG & 0.021 & 2.333 & 28 \\
\hline Greenan and Guellec (2000) & Journal article & France & Firm (13126) & 1985-1991 & $\begin{array}{l}\text { Process and Product } \\
\text { Innovation, Innovation } \\
\text { count }\end{array}$ & Undifferentiated & Mixed & OLS & 0.051 & 3.885 & 10 \\
\hline Greenhalgh et al (2001) & Journal article & UK & Firm (151) & 1987-1994 & IPA, R\&D & Undifferentiated & Mixed & FE WG & 0.082 & 2.140 & 28 \\
\hline Greenhalgh et al (2011) & Working paper & UK & Firm (7038) & 2000-2006 & IPA & Undifferentiated & Mixed & FE WG & 0.022 & 4.119 & 11 \\
\hline $\begin{array}{l}\text { Lachenmaier and Rottmann } \\
\text { (2006) }\end{array}$ & Working paper & Germany & Firm (4567) & $1982-2003$ & $\begin{array}{l}\text { Product and Process } \\
\text { Innovation }\end{array}$ & $\begin{array}{l}\text { Both product and } \\
\text { process }\end{array}$ & Mixed & OLS & 0.057 & 4.063 & 8 \\
\hline $\begin{array}{l}\text { Lachenmaier and Rottmann } \\
\text { (2011) }\end{array}$ & Journal article & Germany & Firm (690) & 1982-2002 & $\begin{array}{l}\text { R\&D, Process and Product } \\
\text { Innovation }\end{array}$ & Undifferentiated & Mixed & GMM & 0.019 & 1.633 & 40 \\
\hline Lucchese and Pianta (2012) & Journal article & OECD mixed & Sector (21) & $1995-2007$ & $\begin{array}{l}\text { Process and Product } \\
\text { Innovation }\end{array}$ & $\begin{array}{l}\text { Both product and } \\
\text { process }\end{array}$ & Mixed & WLS & 0.062 & 1.003 & 2 \\
\hline Mastrostefano and Pianta (2009) & Journal article & OECD mixed & Sector (10) & 1994-2001 & Product innovation & Product & Mixed & OLS & 0.242 & 2.050 & 4 \\
\hline
\end{tabular}




\begin{tabular}{|c|c|c|c|c|c|c|c|c|c|c|c|}
\hline Osterman (1986) & Journal article & US & Industry (40) & 1972-1978 & ICT & Undifferentiated & Skilled & OLS & 0.054 & 0.331 & 6 \\
\hline Pianta (2000) & Book chapter & OECD mixed & Sector (49) & $1989-1993$ & $\begin{array}{l}\text { R\&D, Process and Product } \\
\text { Innovation }\end{array}$ & Undifferentiated & Mixed & OLS & 0.177 & 1.720 & 17 \\
\hline Piva and Vivarelli (2004a) & Journal article & Italy & Firm (488) & 1989-1997 & $\mathrm{R} \& \mathrm{D}$ & Undifferentiated & Skilled & SUR & -0.017 & -0.335 & 2 \\
\hline Piva and Vivarelli (2004b) & Journal article & Italy & Firm (318) & $1992-1997$ & $\mathrm{R} \& \mathrm{D}$ & Undifferentiated & Mixed & FE WG & 0.019 & 0.775 & 6 \\
\hline Rottmann and Ruschinski (1998) & Journal article & Germany & Firm (1982) & 1980-1992 & $\begin{array}{l}\text { Product and Process } \\
\text { Innovation }\end{array}$ & $\begin{array}{l}\text { Both product and } \\
\text { process }\end{array}$ & Mixed & IV & -0.003 & -0.252 & 4 \\
\hline Smolny (1998) & Journal article & Germany & Firm (2405) & 1980-1992 & $\begin{array}{l}\text { Product and Process } \\
\text { Innovation }\end{array}$ & $\begin{array}{l}\text { Both product and } \\
\text { process }\end{array}$ & Mixed & OLS & 0.021 & 2.550 & 2 \\
\hline Smolny (2002) & Journal article & Germany & Firm (2405) & 1980-1992 & $\begin{array}{l}\text { Product and Process } \\
\text { Innovation }\end{array}$ & $\begin{array}{l}\text { Both product and } \\
\text { process }\end{array}$ & Mixed & OLS & 0.029 & 2.800 & 2 \\
\hline Srour et al (2013) & Working paper & Turkey & Firm (17462) & $1980-2001$ & $\mathrm{R} \& \mathrm{D}, \mathrm{IPA}$ & Undifferentiated & Unskilled & OLS & 0.011 & 3.024 & 12 \\
\hline van Reenen (1997) & Journal article & UK & Firm (598) & 1977-1982 & $\begin{array}{l}\text { IPA, Innovation count, } \\
\text { Product and Process } \\
\text { Innovation }\end{array}$ & Undifferentiated & Mixed & OLS & 0.027 & 1.251 & 105 \\
\hline Westermann and Schaefer (2001) & Journal article & Germany & Firm (450) & 1981-1993 & ICT & Undifferentiated & Mixed & OLS & 0.155 & 2.779 & 12 \\
\hline Yang and Lin (2008) & Journal article & Non OECD & Firm (492) & $1997-2003$ & $\begin{array}{l}\text { IPA, R\&D, Process and } \\
\text { Product Innovation }\end{array}$ & Undifferentiated & Mixed & GMM & 0.036 & 1.801 & 37 \\
\hline Yochum and Rhiel (1990) & Journal article & US & Industry (1) & 1946-1983 & Process Innovation & Process & Mixed & OLS & -0.550 & -3.642 & 2 \\
\hline All & & & & & & & & & 0.036 & 1.850 & 567 \\
\hline
\end{tabular}


Table A2: Summary statistic for moderating variables

\begin{tabular}{|c|c|c|c|c|c|}
\hline Moderating variables & Obsn. & Mean & Std Dev & Min & Max \\
\hline \multicolumn{6}{|l|}{ Effect indicators } \\
\hline PCC & 567 & 0.058 & 0.152 & -0.619 & 0.906 \\
\hline Standard error of PCC & 567 & 0.051 & 0.072 & 0.004 & 0.267 \\
\hline Precision & 567 & 60.282 & 56.107 & 3.742 & 284.462 \\
\hline \multicolumn{6}{|l|}{ Publication type and date } \\
\hline Journal article & 567 & 0.637 & 0.481 & 0 & 1 \\
\hline Publication date after 2000 & 567 & 0.536 & 0.499 & 0 & 1 \\
\hline \multicolumn{6}{|l|}{ Model specification } \\
\hline Informed by theoretical DLDM & 567 & 0.760 & 0.427 & 0 & 1 \\
\hline Dynamic specification allowed & 567 & 0.295 & 0.456 & 0 & 1 \\
\hline Time dummies included & 567 & 0.356 & 0.479 & 0 & 1 \\
\hline Industry or sector dummies & 567 & 0.236 & 0.425 & 0 & 1 \\
\hline Wage included in labour demand model & 567 & 0.515 & 0.500 & 0 & 1 \\
\hline Output included in labour demand model & 567 & 0.598 & 0.491 & 0 & 1 \\
\hline Capital included in labour demand model & 567 & 0.388 & 0.488 & 0 & 1 \\
\hline Long-term effect (3 lags or more) & 567 & 0.127 & 0.333 & 0 & 1 \\
\hline \multicolumn{6}{|l|}{ Sample characteristics } \\
\hline Data type: Panel & 567 & 0.714 & 0.452 & 0 & 1 \\
\hline Industry or sector data & 567 & 0.233 & 0.423 & 0 & 1 \\
\hline Innovation measure: $R \& D$ & 567 & 0.217 & 0.413 & 0 & 1 \\
\hline Innovation measure: IPA & 567 & 0.159 & 0.366 & 0 & 1 \\
\hline Innovation type: Process & 567 & 0.118 & 0.323 & 0 & 1 \\
\hline Innovation type: Product & 567 & 0.122 & 0.327 & 0 & 1 \\
\hline Innovation measure: ICT & 567 & 0.122 & 0.327 & 0 & 1 \\
\hline Innovation measures: R\&D + IPA & 567 & 0.249 & 0.433 & 0 & 1 \\
\hline $\begin{array}{l}\text { Newness of Innovation: First to country or } \\
\text { industry }\end{array}$ & 567 & 0.002 & 0.042 & 0 & 1 \\
\hline Skill type: Unskilled labour & 567 & 0.076 & 0.265 & 0 & 1 \\
\hline Sector: Manufacturing & 567 & 0.873 & 0.333 & 0 & 1 \\
\hline Canada data & 567 & 0.016 & 0.125 & 0 & 1 \\
\hline France data & 567 & 0.019 & 0.138 & 0 & 1 \\
\hline Germany data & 567 & 0.168 & 0.374 & 0 & 1 \\
\hline Italy data & 567 & 0.019 & 0.138 & 0 & 1 \\
\hline Netherlands data & 567 & 0.004 & 0.059 & 0 & 1 \\
\hline Norway data & 567 & 0.005 & 0.073 & 0 & 1 \\
\hline Spain data & 567 & 0.053 & 0.224 & 0 & 1 \\
\hline Sweden data & 567 & 0.041 & 0.197 & 0 & 1 \\
\hline UK data & 567 & 0.302 & 0.459 & 0 & 1 \\
\hline US data & 567 & 0.168 & 0.374 & 0 & 1 \\
\hline OECD Countries data & 567 & 0.917 & 0.276 & 0 & 1 \\
\hline High innovation intensity & 567 & 0.120 & 0.325 & 0 & 1 \\
\hline Firm size: Large & 567 & 0.028 & 0.166 & 0 & 1 \\
\hline \multicolumn{6}{|l|}{ Estimation method } \\
\hline GMM & 567 & 0.196 & 0.397 & 0 & 1 \\
\hline Differenced/within estimators & 567 & 0.713 & 0.453 & 0 & 1 \\
\hline
\end{tabular}


Table A3: Robustness check 1: PET/FAT/PEESE results using sampling weights

\begin{tabular}{|c|c|c|c|c|c|c|c|c|c|c|c|}
\hline \multirow[b]{3}{*}{ Dependent variable: $\mathrm{t}$-value } & \multicolumn{6}{|c|}{ Panel A } & \multicolumn{5}{|c|}{ Panel B } \\
\hline & (1a) & $(2 a)$ & $(3 a)$ & (4a) & $(5 a)$ & $(6 a)$ & (1b) & $(3 b)$ & (4b) & $(5 b)$ & $(6 b)$ \\
\hline & $\mathrm{PET} / \mathrm{FAT}$ & PET/FAT & $\mathrm{PET} / \mathrm{FAT}$ & $\mathrm{PET} / \mathrm{FAT}$ & PET/FAT & PET/FAT & PEESE & PEESE & PEESE & PEESE & PEESE \\
\hline$\beta$ & $\begin{array}{c}0.032 * * \\
(0.014)\end{array}$ & $\begin{array}{c}0.007 \\
(0.005)\end{array}$ & $\begin{array}{c}0.031 * * * \\
(0.008)\end{array}$ & $\begin{array}{c}0.026 * * * \\
(0.003)\end{array}$ & $\begin{array}{c}0.004^{*} \\
(0.002)\end{array}$ & $\begin{array}{c}0.016 * * * \\
(0.006)\end{array}$ & $\begin{array}{c}0.020 * * * \\
(0.006)\end{array}$ & $\begin{array}{c}0.035^{* * *} * \\
(0.007)\end{array}$ & $\begin{array}{c}0.027 * * * \\
(0.003)\end{array}$ & $\begin{array}{c}0.005 * * \\
(0.002)\end{array}$ & $\begin{array}{c}0.021 * * * \\
(0.006)\end{array}$ \\
\hline$\alpha$ & $\begin{array}{l}-1.686 \\
(1.243)\end{array}$ & $\begin{array}{c}1.979 * * * \\
(0.158)\end{array}$ & $\begin{array}{c}0.556 \\
(0.535)\end{array}$ & $\begin{array}{c}0.357 \\
(0.552)\end{array}$ & $\begin{array}{c}0.170 \\
(0.317)\end{array}$ & $\begin{array}{c}0.857 * * \\
(0.428)\end{array}$ & & & & & \\
\hline Std. error & & & & & & & $\begin{array}{c}-21.466^{* * * *} \\
(2.871)\end{array}$ & $\begin{array}{c}5.228 \\
(4.866)\end{array}$ & $\begin{array}{c}2.242 \\
(1.470)\end{array}$ & $\begin{array}{c}0.558 \\
(1.640) \\
\end{array}$ & $\begin{array}{c}0.886 \\
(5.593) \\
\end{array}$ \\
\hline Observations & 66 & 69 & 344 & 44 & 43 & 567 & 66 & 344 & 42 & 43 & 567 \\
\hline Studies & 14 & 13 & 21 & 7 & 7 & 35 & 14 & 21 & 7 & 7 & 35 \\
\hline
\end{tabular}

Notes: The bivariate meta-regression models are estimated with sampling weights to ensure that the weight of each study in the sample is equal to one. See notes under Table 1 in the main text for model diagnostics and description of the evidence clusters. 
Table A4: Multivariate meta-regression results: General model

\begin{tabular}{|c|c|c|c|}
\hline \multicolumn{4}{|l|}{ Dependent variable: $t$-value } \\
\hline Precision & $\begin{array}{c}-0.014 \\
(0.023)\end{array}$ & Sector: Manufacturing & $\begin{array}{c}0.045^{* * * *} \\
(0.012)\end{array}$ \\
\hline Publication type and date & & Canada data & $-0.053 * *$ \\
\hline Journal article & 0.005 & & $(0.024)$ \\
\hline \multirow{3}{*}{ Publication date after 2000} & $(0.008)$ & France data & 0.003 \\
\hline & $0.023 *$ & & $(0.023)$ \\
\hline & $(0.012)$ & Germany data & -0.001 \\
\hline Model specification & & & $(0.013)$ \\
\hline Informed by theoretical DLDM & $\begin{array}{l}-0.003 \\
(0.010)\end{array}$ & Italy data & $\begin{array}{l}-0.002 \\
(0.017)\end{array}$ \\
\hline Dynamic model utilized & $\begin{array}{c}0.005 \\
(0.008)\end{array}$ & Netherlands data & $\begin{array}{c}-0.017 \\
(0.065)\end{array}$ \\
\hline Time dummies included & $\begin{array}{l}-0.007 \\
(0.007)\end{array}$ & Norway data & $\begin{array}{c}0.001 \\
(0.047)\end{array}$ \\
\hline Industry or sector dummies included & $\begin{array}{c}0.006 \\
(0.007)\end{array}$ & Spain data & $\begin{array}{c}-0.008 \\
(0.017)\end{array}$ \\
\hline Wage included in model & $\begin{array}{c}0.003 \\
(0.006)\end{array}$ & Sweden data & $\begin{array}{c}-0.016 \\
(0.012)\end{array}$ \\
\hline Output included in model & $\begin{array}{l}-0.016 \\
(0.014)\end{array}$ & UK data & $\begin{array}{c}0.022 \\
(0.019)\end{array}$ \\
\hline Capital included in model & $\begin{array}{c}0.001 \\
(0.008)\end{array}$ & US data & $\begin{array}{c}0.074 * * * \\
(0.020)\end{array}$ \\
\hline Long-term effect (3 lags or more) & $\begin{array}{c}-0.015^{* *} \\
(0.006)\end{array}$ & OECD countries data & $\begin{array}{l}0.026^{*} \\
(0.015)\end{array}$ \\
\hline \multicolumn{2}{|l|}{ Sample characteristics } & High innovation intensity & $-0.034 * * *$ \\
\hline \multirow{2}{*}{ Data type: Panel } & -0.014 & & $(0.006)$ \\
\hline & $(0.016)$ & Firm size: Large & -0.012 \\
\hline \multirow[t]{2}{*}{ Industry of sector data } & $0.035^{*}$ & & $(0.013)$ \\
\hline & $(0.019)$ & Estimation method & \\
\hline Innovation measure: R\&D & $\begin{array}{l}-0.003 \\
(0.006)\end{array}$ & Estimator: GMM & $\begin{array}{l}-0.002 \\
(0.004)\end{array}$ \\
\hline Innovation measure: IPA & $\begin{array}{c}-0.012 * * \\
(0.005)\end{array}$ & Differenced / within & $\begin{array}{c}-0.013 * * * \\
(0.004)\end{array}$ \\
\hline Innovation measure: ICT & $\begin{array}{c}0.098 * * \\
(0.049)\end{array}$ & Constant & $\begin{array}{c}0.048 \\
(0.399)\end{array}$ \\
\hline \multirow[t]{2}{*}{ Innovation measures: R\&D + IPA } & -0.005 & Observations & 567 \\
\hline & $(0.006)$ & Studies & 35 \\
\hline \multirow[t]{2}{*}{ Innovation type: Process } & -0.009 & LR Test chi ${ }^{2}$ & 242 \\
\hline & $(0.007)$ & $\mathrm{P}>\mathrm{chi}^{2}$ & 0.000 \\
\hline \multirow[t]{2}{*}{ Innovation type: Product } & $-0.013 *$ & Log-likelihood (HM) & -1218.331 \\
\hline & $(0.007)$ & Log-likelihood (Comp. model) & -1226.925 \\
\hline \multirow[t]{2}{*}{ Innovation is first to industry or country } & -0.044 & VIF & 13.41 \\
\hline & $(0.030)$ & Heterogeneity ${ }^{\#}$ & $79 \%$ \\
\hline Skill type: Unskilled labour & $\begin{array}{c}-0.024 * * * \\
(0.004)\end{array}$ & Estimation & HM2-RI \\
\hline
\end{tabular}




\section{Notes}

${ }^{1}$ See Katsoulacos (1984) on the difference between the employment effects of process and product innovation.

2 See Griliches (1992) on the measurement of knowledge spillovers and the lag structure in the relationship between R\&D spillovers and productivity.

${ }^{3}$ Although excluded in this meta-analysis, findings based on the skill/wage share or innovation-decomposition models deserve separate reviews.

${ }^{4}$ We exclude the outliers from estimation if they are found to have undue influence (i.e., if they are associated with a dfbeta statistic greater than one in magnitude).

${ }^{5}$ These magnitudes are smaller than those in Cohen (1988), who suggests that the PCC represents small effect if its absolute value is less than 0.10 , medium effect if it is 0.25 , and large if it is greater than 0.4 . We adopt

Doucouliagos (2011) guidelines as the latter take into account the observed distribution of 22,000 PCCs from a range of fields in economics research.

${ }^{6}$ The heterogeneity measure is a generalization of Cochran's $\mathrm{Q}$ and indicates the proportion of residual betweenstudy variation due to heterogeneity, as opposed to within-study sampling variability (Harbord and Higgins, 2008). Higgins et al. (2003) suggest that heterogeneity is low if the measure is between $25 \%-50 \%$, moderate if it is between $51 \%-75 \%$, and high if over $75 \%$.

${ }^{7}$ There is a mistaken presumption that the Egger et al. (1997) model makes the detection of publication selection bias almost inevitable because of the positive association between effect-size estimates and their standard errors (or because of the negative association between effect-size estimates and their precision). On the contrary, simulation results in Stanley (2008) indicate that the funnel asymmetry test based on Egger et al (1997) has low power - i.e., it tends to fail detecting publication selection when the latter actually exists.

${ }^{8}$ The evidence pools are the same as those that underpins the funnel graphs above.

${ }^{9}$ As a further check, we also compare the log-likelihood ratio for alternative estimators and for different HM specifications. A smaller log-likelihood value in magnitude provides additional evidence in favour of the estimator/specification at hand.

${ }^{10}$ Katsoulacos (1986: 12) reports that his theoretical results lend support to the "often quoted empirical observation ... that product innovation is more likely to have a favourable employment effect than process innovation."

${ }^{11}$ We have checked the data and established that the relatively smaller estimates based on high-innovationintensity firms/industries is NOT due to preponderance of industry-level estimates in our sample. We have established that the total number of studies and observations for high-innovation-intensity estimates are 6 and 68 , respectively. Of the 6 studies (Akcigit and Kerr, 2012; Bogliacino et al, 2012; Buerger et al, 2012; Coad and Rao, 2011; Greenhalgh et al, 2001; and Lachenmaier and Rottmann, 2011) only one (Buerger et al, 2012) utilizes industry-level data. Of the 68 estimates, only 24 are based on industry-level data.

${ }^{12}$ As Griliches and Mairesse (1995: 22) have noted in the context of R\&D productivity literature, much of the work "has been guided ... by what 'econometrics' as a technology might be able to do ... rather than focusing on the more important but technically less tractable problems of data quality and model specification."

${ }^{13}$ PEESE estimates are presented only if the PET/FAT estimates indicate significant effect-size estimate beyond selection bias. PET/FAT estimates are available on request.

${ }^{14}$ The ranking is based on 2003 data for labour-market flexibility and on 1998, 2003 and 2008 data for productmarket regulation.

${ }^{15}$ With Hicks-neutral technology, the relative factor shares remain constant for a given capital-output ratio $(\mathrm{K} / \mathrm{L})$ ratio. Harrod-neutral technology is labour-augmenting in that the relative factor shares remain constant at a given capital-output ratio. Finally, the Solow-neutral technology is capital-augmenting and leaves relative the factor shares constant at any labour-output ratio. 